\title{
Depth Constraints on Azimuthal Anisotropy in the Great Basin from Rayleigh-wave Phase Velocity Maps ${ }^{\text {th }}$
}

\author{
Caroline Beghein ${ }^{\mathrm{a}, *, 1}$, J. Arthur Snoke ${ }^{\mathrm{b}}$, Matthew J. Fouch ${ }^{\mathrm{c}}$ \\ ${ }^{a}$ University of California Los Angeles, Department of Earth and Space Sciences, 595 \\ Charles Young Drive East, Box 951567, Los Angeles, CA 90095-1567, United States \\ ${ }^{b}$ Department of Geosciences Virginia Polytechnic Institute and State University, 4044, \\ Derring Hall (0420), Blacksburg, VA 24061, United States \\ ${ }^{c}$ School of Earth and Space Exploration, Arizona State University, Bateman Physical \\ Sciences Center F-wing, Tempe, AZ 85287, United States
}

\section{Abstract}

We present fundamental mode Rayleigh-wave azimuthally anisotropic phase velocity maps obtained for the Great Basin region at periods between $16 \mathrm{~s}$ and $102 \mathrm{~s}$. These maps offer the first depth constraints on the origin of the semi-circular shear-wave splitting pattern observed in central Nevada, around a weak azimuthal anisotropy zone. A variety of explanations have been proposed to explain this signal, including an upwelling, toroidal mantle flow around a slab, lithospheric drip, and a megadetachment, but no consensus has been reached. Our phase velocity study help constrain the three-dimensional anisotropic structure of the upper mantle in this region and contribute to a better understanding of the deformation mechanisms taking place beneath the western United States. The dispersion measurements were made using data from the USArray Transportable Array. At

\footnotetext{
Email addresses: cbeghein@ucla.edu (Caroline Beghein)
}

${ }^{1}+13108250742$ 
periods of $16 \mathrm{~s}$ and $18 \mathrm{~s}$, which mostly sample the crust, we find a region of low anisotropy in central Nevada coinciding with locally reduced phase velocities, and surrounded by a semi-circular pattern of fast seismic directions. Away from central Nevada the fast directions are $\sim \mathrm{N}-\mathrm{S}$ in the eastern Great Basin, NW-SE in the Walker Lane region, and they transition from E-W to N-S in the northwestern Great Basin. Our short period phase velocity maps, combined with recent crustal receiver function results, are consistent with the presence of a semi-circular anisotropy signal in the lithosphere in the vicinity of a locally thick crust. At longer periods (28-102 s), which sample the uppermost mantle, isotropic phase velocities are significantly reduced across the study region, and fast directions are more uniform with an $\sim \mathrm{E}-\mathrm{W}$ fast axis. The transition in phase velocities and anisotropy can be attributed to the lithosphere-asthenosphere boundary at depths of $\sim 60 \mathrm{~km}$. We interpret the fast seismic directions observed at longer periods in terms of present-day asthenospheric flow-driven deformation, possibly related to a combination of Juan de Fuca slab rollback and eastward-driven mantle flow from the Pacific asthenosphere. Our results also provide context to regional SKS splitting observations. We find that our short period phase velocity anisotropy can only explain $\sim 30 \%$ of the SKS splitting times, despite similar patterns in fast directions. This implies that the origin of the regional shear-wave splitting signal is complex and must also have a significant sublithospheric component. Key words: Rayleigh-waves, Anisotropy, Lithosphere, Asthenosphere, Crust, USArray, Great Basin 


\section{Introduction}

2

3

4

The Great Basin is located in the northern part of the Basin and Range Province in the western United States, and covers most of the state of Nevada, the southern part of Oregon, and the western part of Colorado (Figure 1). It is delimited to the west by the Sierra Nevada, to the north by the Snake River Plain, and to the east by the Colorado Plateau. The region is characterized by an average crustal thickness of about $30 \mathrm{~km}$ (Priestley et al., 1980; Catchings and Mooney, 1991; Zandt et al., 1995; Sheehan et al., 1997; Das and Nolet, 1998; Lerch et al., 2007) above a thin ( 30 to $40 \mathrm{~km}$ ) mantle lid (Burdick and Helmberger, 1978; Zandt et al., 1995). The presence of this thin lithosphere is probably the result of a large degree of lithospheric-scale extension (Hammond and Thatcher, 2004; Wernicke et al., 2008), but the details of lithospheric deformation constraints are not well known. In particular, the relationship between upper mantle processes and their surface tectonic signature is still rather poorly constrained in this region. Further, fundamental questions remain regarding the depth distribution of deformation and the interaction between the crust, the upper mantle lithosphere and the asthenosphere (Silver and Holt, 2002; Becker et al., 2006; Wernicke et al., 2008).

Seismic anisotropy, the dependence of seismic wave velocity with the direction of propagation or polarization of the wave, is a powerful tool that can give unique information about mantle deformation. In the crust it can result from the shape preferred orientation of fluid-filled cracks or lenses in responses to stress, and can be related to the presence of faults (Crampin et al., 1984). In the upper mantle, it is believed to be due to the lattice pre- 
ferred orientation (LPO) of elastically anisotropic minerals, such as olivine. In the lithospheric mantle, the preferred alignment of olivine, or frozen-in anisotropy, is often attributed to deformation due to past tectonic processes (Karato and Toriumi, 1989; Ben-Ismail and Mainprice, 1998; Holtzman et al., 2003), while in the asthenosphere there is a general agreement that it is related to present-day deformation (Nicolas et al., 1987; Smith et al., 2004; Marone and Romanowicz, 2007). The fast direction of wave propagation has been shown to be, in general, a good proxy for mantle flow when the flow is a progressive simple shear (Ribe, 1989; Becker et al., 2003). In some cases (presence of water or partial melt), however, the relation between shear direction and seismic fast direction can be more complicated, making the interpretation of seismic anisotropy in terms of mantle deformation more challenging (Jung and Karato, 2001; Holtzman et al., 2003).

Shear-wave splitting constitutes a simple and relatively unambiguous manifestation of seismic anisotropy (Mitchell and Helmberger, 1973), and combined with geodynamic modeling it can provide information about mantle deformation. In the western US, the interpretation of those results is, however, still controversial (Silver and Holt, 2002; Becker et al., 2006; Zandt and Humphreys, 2008; West et al., 2009). Specifically, shear-wave splitting studies show a semi-circular pattern of polarization directions surrounding a region of low splitting in central Nevada (Savage and Sheehan, 2000; West et al., 2009). The location of the anisotropy-low also coincides with a locally thick crust (Ozalaybey et al., 1997), a Bouguer gravity low (Simpson et al., 1986), and regionally reduced heat flow (Sass et al., 1994). The anisotropy pattern was initially interpreted as being caused by an upwelling (Savage and 
Sheehan, 2000), and later as due to toroidal mantle flow around the edge of the Gorda-Juan de Fuca slab (Zandt and Humphreys, 2008). A more recent hypothesis is that of a lithospheric drip (West et al., 2009), based on the presence of a high-velocity cylinder in the mantle beneath the Great Basin (Roth et al., 2008) combined with the lack of young volcanism and the presence of a local heat flow low. Decoupling between the crust and the mantle accompanied by a megadetachment in the Great Basin was also recently proposed (Wernicke et al., 2008).

There is thus a variety of possible explanations for these shear-wave splitting observations, and better depth constraints on the origin of the anisotropy signal are thus needed to improve our understanding of the deformation processes taking place beneath this region. One of the fundamental difficulties in interpreting shear-wave splitting data in terms of mantle deformation lies in the fact that analyses must be made using waves with nearly vertical incidence. shear-wave splitting therefore cannot provide constraints on the depth of origin or depth distribution of the azimuthal anisotropy. Surface waves and their dispersion properties are better suited for that purpose.

In this study we thus measured the dispersion of Rayleigh-wave fundamental mode phase velocities over the period range 16 s to 170 s recorded from teleseisms on stations in the dense ( $\sim 70 \mathrm{~km}$ spacing) USArray Transportable Array. We employed a traditional two-station method to determine inter-station phase velocities, which were then inverted to obtain azimuthally anisotropic phase velocity maps. The high density of seismic stations deployed in our study area enabled us to model azimuthal changes in Rayleighwave phase velocity with higher resolution than previously obtained for the 
region. In addition, the use of surface waves allowed us, for the first time, to put some constraints on the depth of origin of the azimuthal anisotropy signal detected with shear-wave splitting in central Nevada. This will help shed light on the origin of the shear-wave splitting observations in the region.

\section{Data selection and preparation}

We analyzed vertical component seismograms for events recorded by the USArray Transportable Array (TA) broadband seismic stations. These stations were deployed in Nevada starting in 2006 in the framework of the Earthscope project with an average station spacing of $70 \mathrm{~km}$. We initially selected 59 teleseisms of minimum magnitude 5.0 and maximum depth of $200 \mathrm{~km}$, which occurred between October 2006 and October 2007 and for which Rayleigh-waves were recorded by the TA stations. Not all stations were in place during the entire period of this study, so the earliest events were recorded by fewer stations than those that occurred later on. We processed the seismograms for all the stations by correcting for the instrument response, decimating to 1 sample per second, and integrating to displacement.

For each earthquake, we then performed a frequency-time analysis (FTAN) (Dziewonski et al., 1969; Landisman et al., 1970) to identify the appropriate range of group velocities and to assess the quality of the group-velocity spectrum. Figure 2 shows examples of FTAN plots for vertical-component instrument-corrected waveforms at two stations along a common great-circle path from an event in our dataset. In both plots, the contours are smooth and well-behaved over periods that include the entire targeted period range. 
We rejected stations and sometimes the event for which the FTAN plots displayed irregularities. Such irregularities can be caused by small magnitude (leading to low signal-to-noise $(\mathrm{S} / \mathrm{N})$ ratio at the highest and lowest frequencies), complicated source function, paths that cross tectonic boundaries at sharp angles leading to multi-pathing, or frequency-dependent scattering from heterogeneities along the path (Deschamps et al., 2008a; Meier et al., 2004). Rejecting events or stations with irregular FTAN plots reduces possible artifacts due to finite frequency effects.

\section{Rayleigh-wave phase velocity dispersion measurements}

The analysis procedure is a two-station method developed by Snoke and his colleagues, based on Herrmann's developments (Herrmann, 1987) to determine inter-station dispersion phase velocities. This method has a long history (Sato, 1955; Knopoff, 1972) and enables measurements of phase velocities between two stations that share a common great-circle path with an event. This assumes that the deconvolution of the near-station waveform from the far-station waveform removes the effects on the calculated dispersions of the structure between the epicenter and the near station. It has the advantage of reducing errors due to spectral anomalies that can be caused by the focal mechanism. For each earthquake, we thus identified and selected pairs of stations for which the difference (dbaz) between the backazimuths of the far station to the epicenter and to the near station was smaller than $3^{\circ}$ to insure that the stations are aligned to a good approximation with a common great circle path. This restriction limits the number of usable events, but the dense network of TA stations enabled us to find many suitable station pairs 
for a total of 28 teleseisms (Figure 3 and Table 1). Rayleigh-wave dispersion analyses were carried out for these 28 events.

We use a variant of the method developed by Herrmann (1987) to calculate estimates of interstation phase velocities and phase velocity errors from vertical-component waveforms for each identified station-pair. The method (see details in Warren et al. (2008)) uses coherencies and cross correlations for the two waveforms and calculates the full spectrum of the inter-station phase velocities in one step. The use of a reference phase-velocity spectrum calculated for a reference Earth model improves the coherence and typically removes the need for phase unwrapping. For the reference Earth model, we used a composite model, modified from the Tectonic North America (TNA) model (Grand and Helmberger, 1984), which is an upper mantle shear-wavevelocity model. We added the P-wave velocities and densities from model AK135 (Kennett et al., 1995), and the Catchings and Mooney (1991) Basin and Range crustal model. We call our reference model mTNA. The method provides a standard deviation estimate for the phase velocity at each frequency based on the coherency of the two waveforms after the near-station record has been time-shifted to the far-station time using the calculated phase velocities (Figure 4). A further data quality control was then performed by inspection of the power spectrum (Figure 4(B)). Station pairs for which the amplitude of the power spectrum decreased too fast were discarded. Depending on the period, this leaves us with between 600 and 850 station pair paths. 


\section{Azimuthally anisotropic phase velocity maps}

\subsection{Inversion of the path-averaged measurements}

The measurements $\bar{c}$ performed with the two-station method are averages of the phase velocity $c$ calculated along the great circle path that connects the two stations considered :

$$
\bar{c}(T)=\int_{\Delta_{1}}^{\Delta_{2}} c(T, l) d l
$$

where $T$ is the period of the wave, and $l$ designates the great circle path between stations 1 and 2 at epicentral distance $\Delta_{1}$ and $\Delta_{2}$, respectively. We constructed phase velocity maps by inversion of equation 1 using the LSQR (Paige and Saunders, 1982) inversion procedure described by Lebedev and van der Hilst (2008). Uncertainties on the phase velocity maps at a given period are estimated using an average of the uncertainties on the pathaveraged measurements.

The LSQR method employed allows us to model changes in the phase velocity with the azimuth of propagation, and thus determine estimates for seismic azimuthal anisotropy if the backazimuths of our stations cover a range of at least $90^{\circ}$, which is the case for our data set. In a slightly anisotropic medium, the phase velocity can be expressed as a function of the horizontal direction of propagation (azimuth $\Psi$ ) as follows (Smith and Dahlen, 1973) :

$c(T, \Psi)=c_{0}(T)+c_{1}(T) \cos (2 \Psi)+c_{2}(T) \sin (2 \Psi)+c_{3}(T) \cos (4 \Psi)+c_{4}(T) \sin (4 \Psi)$

where $T$ represents the period of the wave. $c_{0}$ is the isotropic (averaged over all azimuths) part of the phase velocity and the other terms describe the 
azimuthal dependence of the phase velocity. This equation can be written as :

$$
\mathbf{d}=\mathbf{G m}
$$

where $\mathbf{m}$ is the vector representing the model parameters $\left(c_{0}, c_{1}, c_{2}, c_{3}\right.$ and $c_{4}$ in equation 2), $\mathbf{d}$ is the data vector, and $\mathbf{G}$ is the matrix describing the physical relationship between observations and model parameters. The directions of fast propagation $\Theta_{2 \Psi}$ and $\Theta_{4 \Psi}$ are obtained by calculating :

$$
\begin{aligned}
\Theta_{2 \Psi} & =\frac{1}{2} \arctan \left(\frac{c_{2}}{c_{1}}\right) \\
\Theta_{4 \Psi} & =\frac{1}{2} \arctan \left(\frac{c_{4}}{c_{3}}\right)
\end{aligned}
$$

and the amplitudes of the anisotropy is given by :

$$
\begin{aligned}
& \Lambda_{2 \Psi}=\sqrt{c_{2}{ }^{2}+c_{1}{ }^{2}} \\
& \Lambda_{4 \Psi}=\sqrt{c_{4}^{2}+c_{3}^{2}}
\end{aligned}
$$

Our data yielded sufficient azimuthal coverage to enable us to estimate the azimuthal dependence of the phase velocities across the Great Basin. We introduced these anisotropic terms in the inversions of the path-averaged phase velocity measurements with a moderate amount of lateral smoothing, and we tested different sized triangular model grids. The choice of the grid spacing is subjective, but should remain smaller than the target resolution, which itself is dependent on the station spacing and the azimuthal coverage achieved. A grid spacing that is too large is equivalent to applying too much smoothing and we would be unable to see potentially interesting model features. A grid spacing too small could display small scale variations, which may not be resolvable. We performed tests using 30, 45, and $60 \mathrm{~km}$. The 


\subsection{Significance of the anisotropy}

We found that including the azimuthal terms in the inversion of equation 2 decreases the total variance compared to inversions including only the $0 \Psi$ terms $\left(c_{0}\right.$ in equation 2$)$. However, this decrease could be due to an increase in the total number of unknowns and not necessarily be required by the data. In order to insure that the anisotropy introduced was statistically significant we adopted the method described by Trampert and Woodhouse (2003). it uses a reduced $\chi^{2}$ defined as :

$$
\chi^{2}=\frac{1}{N-M}(\mathbf{d}-\mathbf{G m}) \mathbf{C}_{\mathbf{d}}^{-1}(\mathbf{d}-\mathbf{G m})
$$

where $C_{d}$ is the data covariance matrix, $N$ is the total number of data, and $M$ is the trace of the resolution matrix $\mathbf{R}$. The resolution matrix cannot be directly obtained from the LSQR method, but it can be calculated by inverting each column $j$ of matrix $\mathbf{G}$ (Trampert and Lévêque, 1990). If $\mathbf{G}_{\mathbf{j}}$ is the vector formed by the $j^{\text {th }}$ column of $\mathbf{G}$ we can solve :

$$
\mathbf{R}_{\mathbf{j}}=\mathbf{L G}_{\mathbf{j}}
$$

where $\mathbf{L}$ represents the LSQR operator. $\mathbf{R}_{\mathbf{j}}$ is then column $j$ of the resolution matrix. The trace of the resolution matrix increases as the applied damping decreases, and $\chi^{2}$ decreases (Figure 5). In order to test whether a decrease 
in $\chi^{2}$ between two inversions is significant, we performed a standard F-test based on the number of free parameters $N-M$ used to construct the models, following Trampert and Woodhouse (2003). Note that here, because the total number of data is the same in each inversion, comparing models based directly on the trace of $\mathbf{R}$ is equivalent to comparing them based on the number of independent variables.

Extensive tests showed that including the $2 \Psi$ terms in equation 2 significantly improved the data fit compared to inversions with the $0 \Psi$ terms only, and adding the $4 \Psi$ terms significantly reduced the $\chi^{2}$ misfit furthermore. An example is given in Figure 5 for measurements made at $38 \mathrm{~s}$ period and shows that, for a given number of independent parameters, $\chi^{2}$ was lowered as the different anisotropy terms were added to the inversions. The F-tests determined that these changes in reduced $\chi^{2}$ are statistically significant : For instance, we calculated that there is a $92 \%$ probability that the reduction in misfit between our "preferred" $0 \Psi+2 \Psi$ inversion and our "preferred" $0 \Psi+2 \Psi+4 \Psi$ inversion is significant. Similar results were found at all periods measured between 16 s and 102 s. We can therefore conclude that the data we collected for these periods require the presence of azimuthal anisotropy to explain the measured phase velocities.

\subsection{Finite Frequency Effects}

The two station method employed here is based on ray theory: it thus assumes that off-great circle path scattering is negligible and that the deconvolution of the near-station waveform from the far-station waveform removes the effects of structure between the epicenter and the near station. However, due to their finite frequencies, surface waves are sensitive to structure outside 
of the great circle path, and the measurements can be affected by diffraction and wavefront interference. Perturbations due to lateral heterogeneities near the great circle path can be accounted for by using 2-D sensitivity kernels (Zhou et al., 2005). The method we employed to generate phase velocity maps from our path-averaged measurements uses a finite width approximation of along-path sensitivity kernels (Lebedev and van der Hilst, 2008).

Whether accounting for finite frequency effects significantly improves the final tomographic models has been vigorously debated over the past few years (van der Hilst and de Hoop, 2005; Yang and Forsyth, 2006; Sieminski et al., 2004; Trampert and Spetzler, 2006). It has been argued that equivalent tomographic models can be obtained with ray or finite frequency theory as long as adequate regularization is chosen (Sieminski et al., 2004). The reason invoked is that the advantages of accounting for finite frequency effects are lost in the null-space when path coverage is not perfect, which is most often the case for the Earth (Trampert and Spetzler, 2006). In this study, we already removed potential scattering artifacts at the FTAN analysis stage by discarding events and/or stations with irregular group velocity plots. We tested whether any remaining finite frequency effects were influencing our results by choosing kernels of varying widths and comparing the calculated phase-velocity maps with those calculated using ray theory. We did not find significant differences in the results.

\section{Results}

Phase velocity maps were obtained from the path-averaged phase velocity measurements made at periods of 16, 18, 20, 22, 25, 28, 33, 38, 44, 54, 68, 
85, 102 s. Note that we also analyzed longer period (128 s and $170 \mathrm{~s}$ ) data, but do not include the corresponding phase velocity maps here because they required strong lateral smoothing and the amplitudes of the final models were very low. We concluded that our measurements are unable to constrain lateral variations in phase velocities with respect to mTNA at these higher periods. The azimuthally anisotropic phase velocity maps obtained between $16 \mathrm{~s}$ and $102 \mathrm{~s}$ are presented in Figure 6. The corresponding ray coverage is shown in Figure 7. Changes in the isotropic part of the phase velocity maps with respect to mTNA were found with peak amplitudes of approximately 2-4\%, as detailed below.

Figure 8 shows the sensitivity kernels, or partial derivatives, of the fundamentalmode phase velocities with respect to $V_{S}$ based on velocity model mTNA. It shows that data analyzed between $16 \mathrm{~s}$ and $20 \mathrm{~s}$ period mostly sample the top $30 \mathrm{~km}$ of the Great Basin, which corresponds to the average crustal thickness for the region. Between $22 \mathrm{~s}$ and about $28 \mathrm{~s}$, the phase velocity maps obtained average structure in the top $\simeq 60 \mathrm{~km}$, i.e., in the crust and the upper mantle lithosphere, and longer period data sample part of the lithosphere and the upper asthenosphere.

Our results (Figure 6) show that lateral changes in the isotropic phase velocities are present at short periods (from 16 to $25 \mathrm{~s}$ ), but they tend to fade at longer periods. Between $28 \mathrm{~s}$ and $68 \mathrm{~s}$ period, the isotropic phase velocities are much more uniform over the Great Basin, with values lower than the phase velocity predicted by mTNA. At $85 \mathrm{~s}$ and $102 \mathrm{~s}$, the northern part of the region appears to be characterized by phase velocities sightly larger than those predicted by mTNA. Making a fair and quantitative comparison 
of our phase velocity maps with maps produced by other groups (Pollitz, 2008; Yang et al., 2008) is not straightforward because of different choices of measurements and inversion techniques, data selection, etc (Trampert, 1998). However, we observed a similarity between our low period (16 s and $18 \mathrm{~s}$ ) maps with the $16 \mathrm{~s}$ map obtained with ambient noise tomography (Yang et al., 2008) : In both cases, there is reduction in phase velocity in south central Nevada. In addition, both sets of short period maps show a lower phase velocity region in the northwest corner of the Great Basin, despite the fact that in our case this corresponds to the edge of our model where data coverage is low. The clear reduction in phase velocity across the region found between $28 \mathrm{~s}$ and $68 \mathrm{~s}$ is consistent with phase velocities in the High Lava Plains, northwest of our study region (Warren et al., 2008).

At most periods, the isotropic phase velocities did not significantly depend on whether azimuthal anisotropy was included in the inversions. The exception was found for data measured at 85 s. In that case, the background phase velocity changed quite significantly with the introduction of anisotropy, but mostly at the edges of our study region, where ray coverage is sparse. This is indicative of the presence of trade-offs between the $0 \Psi, 2 \Psi$, and $4 \Psi$ terms of equation 2 . We note, however, that the $85 \mathrm{~s}$ map obtained without including the anisotropic terms was significantly different from the maps obtained at $68 \mathrm{~s}$ and $102 \mathrm{~s}$, but it became similar to the one obtained at $102 \mathrm{~s}$ when we added the anisotropic terms. This, in addition to the F-test results discussed in section 4.2 , gives us confidence that azimuthal anisotropy is required to explain our measurements.

At most periods, the modeled $2 \Psi$ anisotropy has mean and peak ampli- 
tudes varying approximately between $1 \%$ and $2 \%$ and $2 \%$ and $5 \%$, respectively (Figure 9). These amplitudes should, of course, not be taken at face value since they are affected by the damping and the strongest values tend to be found near the edges of the study region where ray coverage is less dense. Given these caveats, it appears that anisotropy beneath the Great Basin is relatively strong at the shortest periods $(16 \mathrm{~s}-18 \mathrm{~s})$, decreases between $22 \mathrm{~s}$ and $68 \mathrm{~s}$, and then increases at longer periods (85 s and $102 \mathrm{~s}$ ).

Figure 6 also reveals very interesting patterns of azimuthal anisotropy. At short periods (16 s and $18 \mathrm{~s}$ ), we observe a semi-circular pattern of fast seismic directions surrounding a small region (about $200 \mathrm{~km}$ wide) of low azimuthal anisotropy centered near $243^{\circ}$ longitude and $39^{\circ}$ latitude. This peculiar pattern is similar (but not identical) to the shear-wave splitting pattern found in previous studies in the region (Savage and Sheehan, 2000; West et al., 2009). Interestingly, the location of the zone of low-to-zero azimuthal anisotropy found at short periods is also the location of a reduction in phase velocity with respect to the mTNA prediction. The fast direction of propagation thus appears to rotate around the negative phase velocity anomaly. As the period increases, the lower phase velocity region becomes progressively wider and the anisotropy pattern changes. The low-to-null azimuthal anisotropy region is no longer visible, but the anisotropy pattern remains rather complicated. At $44 \mathrm{~s}$ and longer periods, the fast direction in the southern Great Basin is approximately SE-NW, while in the northern part (roughly at the location of the positive phase velocity anomaly visible at $85 \mathrm{~s}$ and $102 \mathrm{~s}$ ) it appears oriented in a more SW-NE direction.

Figure 10 displays synthetic tests performed to determine whether the 
patterns seen in our models can be resolved with our data. The first input model is the outcome of the real data inversion at $18 \mathrm{~s}$, with a zone of no azimuthal anisotropy surrounded by a semi-circular pattern (Figure $10(\mathrm{~A})$ ). We inverted the corresponding synthetic data using the same inter-station paths as the ones employed for the $18 \mathrm{~s}$ inversions. We see that the anisotropic amplitudes are slightly lower after inversion due to the regularization, but the isotropic amplitudes are relatively well recovered (Figure 10 (B)). In addition, the input anisotropy pattern is well recovered, which gives us confidence that the anomalous region is resolved by our shortest period data and not an artifact of the inversion scheme. We also performed synthetic tests at $44 \mathrm{~s}$. The anisotropy in model $\mathrm{C}$ is identical to that of model $\mathrm{A}$ but the phase velocity is assumed to be uniform. The test shows that the amplitude of the isotropic part of the model is relatively well recovered (Figure $10(\mathrm{D})$ ). The azimuthal anisotropy "hole" is, however, not resolved and the anisotropy in the output model is more uniform. Input model $\mathrm{E}$ is identical to input model $\mathrm{C}$, except for a positive phase velocity anomaly that we associate with the region of reduced azimuthal anisotropy. A similar phase velocity map can be expected from the lithospheric drip model proposed by West et al. (2009), where a lithospheric drip induces strong mantle downwelling and locally eliminates azimuthal anisotropy. In output model F, we see that neither the semi-circular anisotropy pattern nor the positive anomaly can be recovered at those periods. This is due to the fact that lateral resolution is not only limited by path coverage and station spacing, but also by the wavelength of the waves analyzed. In this case, the phase velocity of a $44 \mathrm{~s}$ Rayleigh-wave is about $3.7 \mathrm{~km} / \mathrm{s}$ (Figure 6), corresponding to a wavelength 
of approximately $160 \mathrm{~km}$, to be compared with a synthetic anomaly with a $200 \mathrm{~km}$ width. Improvements in lateral resolution at those periods may be obtained in future studies with a more exact application of finite frequency theory than the approximation we employed here (Lebedev and van der Hilst, 2008).

\section{Discussion}

\subsection{Isotropic phase velocities across the Great Basin}

Between periods of $16 \mathrm{~s}$ and $25 \mathrm{~s}$, which sample the thin Great Basin lithosphere, our models are characterized by lateral changes in phase velocity. The local reduction in phase velocity seen at $16 \mathrm{~s}$ and $18 \mathrm{~s}$ (mostly sensitive to crustal depths) in south central Nevada could be due to lateral changes in composition, or (though less likely) changes in temperature. However, a more likely interpretation is that our results document the presence of a locally deeper Moho, consistent with regional receiver function constraints (Ozalaybey et al., 1997; Crotwell and Owens, 2005). To determine the effect of a change in the Moho depth on short-period phase velocities, we used our forward-modeling code (Herrmann, 1987) for the mTNA velocity model with an increase of $5 \mathrm{~km}$ in crustal thickness. This change reduces the phase velocity at $16 \mathrm{~s}$ by about $0.7 \%$, which is consistent with the magnitude of the phase velocity reduction seen in our model at $16 \mathrm{~s}$ period.

Between periods of $28 \mathrm{~s}$ and $68 \mathrm{~s}$, Rayleigh-waves are primarily sensitive to depths between $20 \mathrm{~km}$ and $150 \mathrm{~km}$, but have peak sensitivity between about $40 \mathrm{~km}$ and $80 \mathrm{~km}$. These periods therefore sample the lower part of the mantle lithosphere and the upper asthenosphere. Our results show that 
the isotropic phase velocities at those periods are generally more uniform and lower by about $3 \%$ than those predicted by mTNA. This suggests that the lithosphere is quite thin beneath the Great Basin, perhaps as thin as 50-60 km, in agreement with results by Burdick and Helmberger (1978) and Zandt et al. (1995). Furthermore, the reduced phase velocities at these longer periods provide strong evidence for a warmer asthenospheric mantle than one would conclude based on model mTNA. This result is also consistent with the regionally high heat flow observed across the region (Sass et al., 1994) and may help explain the regional Bouguer gravity low (Simpson et al., 1986). Our models also suggest that the top of the increased velocity cylinder imaged by body wave tomography (Roth et al., 2008) may be located at about $75 \mathrm{~km}$ depth or perhaps slightly deeper. This finding implies that, if the lithospheric drip hypothesis of West et al. (2009) is correct, the drip process may be in its final stages of detaching from the overlying lithospheric plate. We also note that the location of the positive phase velocity anomaly observed at 85 and $102 \mathrm{~s}$ in the northern Great Basin could correspond to the southern edge of the Juan de Fuca slab imaged in P-wave tomography studies (Roth et al., 2008; Sigloch et al., 2008; Burdick et al., 2008; West et al., 2009). Depth inversions of the phase velocity maps are being performed in ongoing work, which will enable us to determine the amplitude of this reduction in velocity, and inferentially temperature, at depth.

\subsection{Azimuthal anisotropy}

Our results demonstrate that seismic azimuthal anisotropy is present over most depths of the crust and uppermost mantle, suggesting that deformation extends to significant depth beneath the Great Basin. This finding 
is in general agreement with previous, larger-scale studies, which detected seismic anisotropy over most of the western US in the crust (Bensen et al., 2008), and in the mantle to depths of at least 200-300 km (Hearn, 1996; Marone and Romanowicz, 2007; Nettles and Dziewonski, 2008). This result also generally agrees with Beghoul and Barazangi (1990) who reported the presence of about $3.2 \%$ variations in seismic wave velocity with the azimuth of propagation in the Great Basin from $P_{n}$ travel time measurements.

At short periods (16 s and $18 \mathrm{~s}$ ), our models are characterized by a semi-circular fast seismic direction surrounding a zone of lower phase velocity and low-to-null azimuthal anisotropy, similar to shear-wave splitting fast polarization directions. At longer periods, the fast direction pattern is generally more homogeneous, apart from a slight change in fast direction in the northwestern Great Basin. This change in fast direction is more strongly visible at $85 \mathrm{~s}$ and $102 \mathrm{~s}$, where it coincides with a lateral change in phase velocity with respect to mTNA predictions. Considering the depth sensitivity of our data (Figure 8), our results suggest that the semi-circular fast direction observed at short periods is of lithospheric origin, and varies over scales of $\sim 50 \mathrm{~km}$. The transition between a complex anisotropy pattern at short periods and a more homogeneous fast direction at longer periods is thus compatible with a two-layer model of azimuthal anisotropy (Marone and Romanowicz, 2007; Deschamps et al., 2008b). In this model, the upper layer anisotropy is attributed to a "frozen-in" manifestation of past deformation mechanisms associated with tectonic events, while the lower layer fast direction reflects current mantle deformation.

The azimuthal anisotropy found at periods of $44 \mathrm{~s}$ and larger could be due 
to the LPO of olivine in relation to Juan de Fuca slab rollback. The change in fast direction seen in the northern portion of the region at $85 \mathrm{~s}$ and $102 \mathrm{~s}$, where phase velocities appear faster than average, could be the signature of a locally modified flow field around the edges of the slab. Conversely, the roughly homogenous E-W fast directions found at longer periods (28 s to 102 s) are consistent with asthenospheric flow-induced LPO of olivine. The direction of asthenospheric flow may be driven by Juan de Fuca / Gorda slab rollback, but is also possibly due to eastward-driven flow from the Pacific asthenosphere. The change in fast directions seen in the northern portion of the region, where phase velocities appear faster than average, could be the signature of a locally modified flow field around the southern edge of the slab.

Because the mantle lithosphere is very thin, it is difficult at this stage to determine whether the semi-circular fast direction signal is located in the crust or the mantle part of the lithosphere. We observe, however, correlations between the anisotropy signal and some geological features, which may indicate a crustal origin for at least part of the shear-wave splitting signal observed in the region (Savage and Sheehan, 2000; West et al., 2009), as discussed in section 6.3. Note, however, that given the current lateral resolution of our models, we cannot tell whether this pattern extends to asthenospheric depths. Further, we estimated that the strength of the anisotropy found at short periods (about $3 \%$ ) would produce roughly $0.4 \mathrm{~s}$ of splitting time, which is about $30 \%$ of the total splitting times observed by West et al. (2009). It therefore suggests that a lithospheric source alone cannot completely account for the observed regional shear-wave splitting observations, 
which implies sublithospheric fabric in the region.

\subsection{The fabric of the Great Basin crust}

In this section we explore the relationship between our models and the tectonics of the Great Basin region. Recently, Wernicke et al. (2008) proposed that the Great Basin is underlain by a crustal megadetachment. The proposed detachment zones are located where the mantle lid is very thin (see their Figure 11), which could correspond to channels where asthenospheric material flows around a region of thicker lithosphere. This could cause basal tractions at the base of the lithosphere, which could be transmitted to the crust and generate fabric within the crust and mantle lithosphere. In this scenario, the flow channel would be located around the central Nevada zone of lower phase velocity and null azimuthal anisotropy, following the fast direction of propagation modeled with surface waves. While our models are not of sufficient resolution to confirm the details of the megadetachment hypothesis, our results are broadly consistent with this model.

An alternative interpretation of the short period anisotropy signal is that it reflects regional crustal deformation. For instance, in the eastern part of the study region, the modeled fast direction is oriented north-south, which is also the general direction of the mountain ranges and north-south trending normal faults in the area. This region of extension may induce shape-preferred orientation of crustal cracks (Savage, 1999), which would be orthogonal to the direction of extension, and would therefore generate $\sim \mathrm{N}-\mathrm{S}$ fast directions. Near the Nevada-California border the fast direction of our $16 \mathrm{~s}$ and $18 \mathrm{~s}$ period phase velocity maps is approximately NW-SE, parallel to the Eastern California Shear Zone/Walker Lane fault system, which accommodates 
at least $20 \%$ of the motion between the North American and Pacific plates (Dokka and Travis, 1990). The Eastern California Shear Zone represents the major zone of transitional deformation between the strike-slip plate boundary to the west and the extensional Great Basin zone to the east, which may generate a shear-driven crustal fabric consistent with our results.

The reduced anisotropy in the central Great Basin is more enigmatic. One possible cause of this reduced zone is that previous crustal cracks associate with extension have closed due to more recent compression (or at least lack of extension) in the central Great Basin as documented by Hammond and Thatcher (2004). One possible cause of this reduction in extension is the presence of a lithospheric drip, as suggested by West et al. (2009), which may cause localized crustal compression (Holt et al., manuscript in preparation). Crustal compression could lead to a deeper Moho, consistent with the isotropic part of our phase velocity maps, as discussed in section 6.1.

\section{Conclusions}

We present azimuthally anisotropic phase velocity maps obtained from fundamental mode Rayleigh-wave measurements made between periods of $16 \mathrm{~s}$ and $102 \mathrm{~s}$, which sample structure in the $\sim 20$ to $200 \mathrm{~km}$ depth range. Our results demonstrate the presence of azimuthal anisotropy over most depths of the crust and uppermost mantle, suggesting deformation that extends to significant depth beneath the Great Basin, and constitute the first depths constraints on the origin of the SKS splitting pattern found in the region (Savage and Sheehan, 2000; West et al., 2009).

We find evidence for a semi-circular fast propagation direction for Rayleigh- 
waves at short periods (16 s and $18 \mathrm{~s}$ ), which are sensitive to crustal depths, around a region of locally reduced phase velocity. This reduction in phase velocity can be explained by the presence of a locally thick crust, in agreement with crustal receiver function studies (Ozalaybey et al., 1997; Crotwell and Owens, 2005). While our short period azimuthal anisotropy signal is similar to the local SKS splitting signal, it can only explain about $30 \%$ of the total splitting times, implying that the origin of the shear-wave splitting is complex and must be partly due to asthenospheric fabric development. At periods of $28 \mathrm{~s}$ and higher, which are mostly sensitive to the lower mantle lithosphere and upper asthenosphere, our azimuthal anisotropy signal is more laterally uniform with a fast $\sim \mathrm{E}-\mathrm{W}$ direction, which we interpret in terms of present mantle deformation, possibly related to slab rollback.

These results shed new light on the different hypotheses that were previously proposed to explain the semi-circular SKS splitting observations in the western US. As argued by West et al. (2009), we rule out the possibility of an upwelling as proposed by Savage and Sheehan (2000), because of the paucity of young volcanism, and the presence of a heat flow low as well as a cylindrical fast velocity anomaly beneath the study region. The idea of toroidal mantle flow around a slab (Zandt and Humphreys, 2008) is more difficult to reconcile with our short periods azimuthal anisotropy maps: this model argues in favor of asthenospheric mantle deformation, and it is not clear how it would generate a semi-circular azimuthal anisotropy pattern in the crust and/or in the mantle lithosphere. The West et al. (2009) lithospheric drip model, however, is not incompatible with our findings. In that model, the lithosphere is dripping down due to a gravitational instability, 
and the azimuthal anisotropy-low is due to a rapid, local shift from horizontal to vertical flow. The locally thick crust associated with a reduction in phase velocity in central Nevada could be a result of vertical extensional forces due to strong mantle downwelling, which locally draws crust down with it. The azimuthal anisotropy signal detected in our $16 \mathrm{~s}$ and $18 \mathrm{~s}$ phase velocity maps could be interpreted in terms of asthenospheric flow channels creating basal traction at the base of the lithosphere, which is transmitted to the crust. Another hypothesis relates the anisotropy signal to crustal deformation, such as the presence of the Eastern California Shear Zone and the north-south trending mountain ranges and normal faults in the eastern part of the study region. This cannot explain, however, the total amplitude of the shear-wave splitting signal and requires an additional mechanism to account for the remaining $\sim 70 \%$ of the signal.

\section{Acknowledgements}

C.B. wishes to thank Sergei Lebedev and Frederic Deschamps for sharing their codes, Linda Warren for kindly shared her scripts in the early stage of the project, and Paul Davis for reviewing the paper before submission. This research was partially funded by NSF grants EAR-0548288 (MJF EarthScope CAREER grant).

\section{References}

Becker, T., Kellogg, J., Ekström, G., O’Connell, R., 2003. Comparison of azimuthal seismic anisotropy from surface waves and finite strain from global mantle-circulation models. Geophys. J. Int. 155, 696-714. 
Becker, T. W., Schulte-Pelkum, V., Blackman, D. K., Kellogg, J. B., O'Connell, R. J., 2006. Mantle flow under the western United States from shear wave splitting. Earth Planet. Sci. Lett. 247, 235-251.

Beghoul, N., Barazangi, M., 1990. Azimuthal anisotropy of velocity in the mantle lid beneath the Basin and Range province. Nature 348 (6301), 536538.

Ben-Ismail, W., Mainprice, D., 1998. An olivine fabric database: an overview of upper mantle fabrics and seismic anisotropy. Tectonophysics 296, 145157.

Bensen, G. D., Ritzwoller, M. H., Shapiro, N. M., 2008. Broadband ambient noise surface wave tomography across the United States. J. Geophys. Res.Solid Earth 113 (B5).

Burdick, L., Helmberger, D., 1978. Upper mantle P velocity structure of western United-States. J. Geophys. Res. 83 (B4), 1699-1712.

Burdick, S., Li, C., Martynov, V., Cox, T., Eakins, J., Mulder, T., Astiz, L., Vernon, F. L., Pavlis, G. L., van der Hilst, R. D., 2008. Upper mantle heterogeneity beneath north america from travel time tomography with global and usarray transportable array data. Seism. Res. Lett. 79 (3), 384392.

Catchings, R., Mooney, W., 1991. Basin and Range crustal and upper mantle structure, northwest to central Nevada. J. Geophys. Res.-Solid Earth and Planets 96 (B4), 6247-6267. 
Crampin, S., Chesnokov, E., Hipkin, R., 1984. Seismic anisotropy: the state of the art. Geophys. J. R. A. S. 76 (1), 1-16.

Crotwell, H., Owens, T., 2005. Automated receiver function processing. Seism. Res. Lett. 76, 702-708.

Das, T., Nolet, G., 1998. Crustal thickness map of the western United States by partitioned waveform inversion. J. Geophys. Res. 103 (B12), 30,02130,038 .

Deschamps, F., Lebedev, S., Meier, T., Trampert, J., 2008a. Azimuthal anisotropy of rayleigh-wave phase velocities in the east-central United States. Geophys. J. Int. 173 (3), 827-843.

Deschamps, F., Lebedev, S., Meier, T., Trampert, J., 2008b. Stratified seismic anisotropy reveals past and present deformation beneath the eastcentral United States. Earth Planet. Sci. Lett. 274, 489-498.

Dokka, R., Travis, C., 1990. Role of the Eastern California Shear Zone in accomodating pacific-north american plate motion. Geophys. Res. Lett. 17 (9), 1323-1326.

Dziewonski, A., Bloch, S., Landisman, M., 1969. A technique for the analysis of transient seismic signals. BSSA 59 (1), 427-444.

Grand, S., Helmberger, D., 1984. Upper mantle shear structure of North America. Geophys. J. R. A. S. 76 (2), 399-438.

Hammond, W., Thatcher, W., 2004. Contemporary tectonic deformation of the basin and range province, western united states: 10 years of observa- 
tion with the global positioning system. J. Geophys. Res.-Solid Earth 109, B08403.

Hearn, T., 1996. Anisotropic $P_{n}$ tomography in the western United States. J. Geophys. Res. 101 (B4), 8403-8414.

Herrmann, R., 1987. Computer programs in seismology. Tech. rep., St. Louis University, St. Louis, Missouri.

Holtzman, B., Kohlstedt, D., Zimmerman, M., Heidelbach, F., Hiraga, T., Hustoft, J., 2003. Melt segregation and strain partitioning: Implications for seismic anisotropy and mantle flow. Science 301, 1227-1230.

Jung, H., Karato, S., 2001. Water-induced fabric transitions in olivine. Science 293, 1460-1463.

Karato, S., Toriumi, M., 1989. Seismic anisotropy; mechanisms and tectonic implications. pp. 393-422.

Kennett, B., Engdahl, E., Buland, R., 1995. Constraints on seismic velocities in the earth from traveltimes. Geophys. J. Int. 122, 108-124.

Knopoff, L., 1972. Observation and inversion of surface-wave dispersion. Tectonophysics 13 (1-4), 497-519.

Landisman, M., Usami, T., Sato, Y., Masse, R., 1970. Contributions of theoretical seismograms to study of modes, rays, and earth. Reviews of Geophysics and Space Physics 8 (3), 533-589. 
Lebedev, S., van der Hilst, R. D., 2008. Global upper-mantle tomography with the automated multimode inversion of surface and S-wave forms. Geophys. J. Int. 173 (2), 505-518.

Lerch, D. W., Glen, J. M. G., Ponce, D. A., Miller, E. L., Colgan, J. P., 2007. Crustal structure of the northwestern Basin and Range province and its transition to unextended volcanic plateaus. Geochemistry Geophysics Geosystems 8, Q02011.

Marone, F., Romanowicz, B., 2007. The depth distribution of azimuthal anisotropy in the continental upper mantle. nature 447, 198-203.

Meier, T., Dietrich, K., Stockhert, B., Harjes, H., 2004. One-dimensional models of shear wave velocity for the eastern Mediterranean obtained from the inversion of Rayleigh wave phase velocities and tectonic implications. Geophys. J. Int. 156, 45-58.

Mitchell, B., Helmberger, D., 1973. Shear velocities at the base of the mantle from observations of S and ScS. J. Geophys. Res. 78, 6009-6020.

Nettles, M., Dziewonski, A. M., 2008. Radially anisotropic shear velocity structure of the upper mantle globally and beneath North America. J. Geophys. Res.-Solid Earth 113.

Nicolas, A., Christensen, N., Fuchs, K., Froidevaux, C., 1987. Composition, Structure and Dynamics of the Lithosphere-Asthenosphere System. Vol. 16. American Geophysical Union, Washington, DC, Ch. Formation of anisotropy in upper mantle peridotites: A review, pp. 111-123. 
Ozalaybey, S., Savage, M., Sheehan, A., Louie, J., Brune, J., 1997. Shearwave velocity structure in the northern basin and range province from the combined analysis of receiver functions and surface waves. BSSA 87 (1), 183-199.

Paige, C., Saunders, M., 1982. LSQR - an algoritm for sparse linear-equations and sparse least-squares. Acm T Math Software 8 (1), 43-71.

Pollitz, F. F., 2008. Observations and interpretation of fundamental mode rayleigh wavefields recorded by the transportable array (usarray). Journal of Geophysical Research 113 (B10).

Priestley, K., Orcutt, J., Brune, J., 1980. Higher mode surface waves and the structure of the Great Basin of Nevada and western Utah. J. Geophys. Res. 85, 7166-7174.

Ribe, N., 1989. Seismic anisotropy and mantle flow. J. Geophys. Res. 94, 4213-4223.

Roth, J., Fouch, M., James, D., Carlson, R., 2008. Three-dimensional seismic velocity structure of the northwestern United States. Geophys. Res. Lett. 35.

Sass, J. H., Lachenbruch, A., Jr., S. P. G., Morgan, P., Priest, S. S., Jr., T. H. M., Munroe, R. J., 1994. Thermal regime of the southern basin and range province: 1 . heat flow data from arizona and the mojave desert of california and nevada. J. Geophys. Res. 99 (B11), 22,093-22,119. 
Sato, Y., 1955. Analysis of dispersed srface waves by means of Fourier transform I. Bull. Earthquake Res. Tokyo Univ. 33, 33-50.

Savage, M., 1999. Seismic anisotropy and mantle deformation: What have we learned from shear wave splitting? Rev. Geophys. 37 (1), 65-106.

Savage, M., Sheehan, A., 2000. Seismic anisotropy and mantle flow from the Great Basin to the Great Plains, western United States. J. Geophys. Res. 105 (B6), 13,715-13,734.

Sheehan, A., Jones, C., Savage, M., Ozalaybey, S., Schneider, J., 1997. Contrasting lithospheric structure between the Colorado Plateau and Great Basin: Initial results from Colorado Plateau - Great Basin PASSCAL experiment. Geophys. Res. Lett. 24 (21), 2609-2612.

Sieminski, A., Lévêque, J., Debayle, E., 2004. Can finite-frequency effects be accounted for in ray theory surface wave tomography? Geophys. Res. Lett. 31.

Sigloch, K., McQuarrie, N., Nolet, G., June 2008. Two-stage subduction history under North America inferred from multiple-frequency tomography. Nature Geoscience.

Silver, P., Holt, W., 2002. The mantle flow field beneath western North America. Science 295 (5557), 1054-1057.

Simpson, R., Jachens, R., Blakely, R., 1986. A new isostatic residual gravity map of the conterminous united states with a discussion on the significance of isostatic residual anomalies. J. Geophys. Res. 91 (88), 8348-8372. 
Smith, D., Ritzwoller, M., Shapiro, N., 2004. Stratification of anisotropy in the Pacific upper mantle. J. Geophys. Res. 109 (B11).

Smith, M., Dahlen, F., 1973. The azimuthal dependence of Love and Rayleigh wave propagation in a slightly anisotropic medium. J. Geophys. Res. 78, $3321-3333$.

Trampert, J., 1998. Global seismic tomography: the inverse problem and beyond. Inverse Problems 14 (3), 371-385.

Trampert, J., Lévêque, J., 1990. Simultaneous iterative reconstruction technique - physical interpretation based on the generalized least-squares solution. J. Geophys. Res.-Solid Earth and Planets 95 (B8), 12553-12559.

Trampert, J., Spetzler, J., 2006. Surface wave tomography: finite-frequency effects lost in the null space. Geophys. J. Int. 164, 394-400.

Trampert, J., Woodhouse, J., 2003. Global anisotropic phase velocity maps for fundamental mode surface waves between 40 and 150 s. Geophys. J. Int. 154, 154-165.

van der Hilst, R., de Hoop, M., 2005. Banana-doughnut kernels and mantle tomography. Geophys. J. Int. 163 (3), 956-961.

Warren, L., Snoke, J., James, D., 2008. S-wave velocity structure beneath the High Lava Plains, Oregon, from Rayleigh-wave dispersion inversion. Earth Planet. Sci. Lett. 274, 121-131.

Wernicke, B., Davis, J., Niemi, N., Luffi, P., Bisnath, S., 2008. Active megadetachment beneath the western United States. J. Geophys. Res. 113. 
672 West, J., Fouch, M., Roth, J., Elkins-Tanton, L., 2009. Vertical mantle flow 673 associated with a lithospheric drip beneath the great basin. Nature Geo674 science.

675 Yang, Y., Forsyth, D. W., 2006. Regional tomographic inversion of the am676 plitude and phase of Rayleigh waves with 2-D sensitivity kernels. Geophys. 677 J. Int. 166, 1148-1160.

678 Yang, Y., Ritzwoller, M. H., Lin, F., Moschetti, M. P., Shapiro, N. M., 2008. 679 Structure of the crust and uppermost mantle beneath the western united 680 states revealed by ambient noise and earthquake tomography. J. Geophys. 681 Res. 113 (B12).

Zandt, G., Humphreys, E., 2008. Toroidal mantle flow through the western U.S. slab window. Geology 36 (4), 295-298.

Zandt, G., Myers, S., Wallace, T., 1995. Crust and mantle structure across the Basin and Range-Colorado plateau boundary at $37^{\circ} \mathrm{N}$ latitude and implications for cenozoic extensional mechanism. J. Geophys. Res. 100 (B6), $10,529-10,548$.

Zhou, Y., Dahlen, F., Nolet, G., Laske, G., 2005. Finite-frequency effects in global surface-wave tomography. Geophys. J. Int. 163, 1087-1111. 
Figure 1: Tectonic setting of the western United States. The white box indicates the boundary of the study region.

Figure 2: Single-station Rayleigh-wave group velocities vs. period for the 15 October 2006 Hawaii event. (A) FTAN plot for station M11A (epicentral distance $\Delta=4482 \mathrm{~km})$ and $(\mathrm{B})$ station $\mathrm{O} 06 \mathrm{~A}(\Delta=4114 \mathrm{~km})$, which are separated by $368.4 \mathrm{~km}$. The difference (dbaz) between the backazimuths of the far station (M11A) to the epicenter and to the near station (O06A) is 1.2 deg. The x's are computer-picked energy maxima for each period, and the vertical lines span $\pm 1 \mathrm{~dB}$. Contours are placed every $3 \mathrm{~dB}$. The corresponding waveforms are shown on the sides.

Figure 3: Selected events location (black stars), stations (black triangles on land), and event-station great circle paths (grey). A few of the 28 selected events have effectively the same location.

Figure 4: (A) Phase velocities calculated from the phase of the coherence of the observed waveforms for the inter-station path between stations M11A and O06A. The error bar for each phase velocity is based on the coherence of the two waveforms after the near-station waveform has been time-shifted to the far-station epicentral distance using the calculated phase velocities. The solid line is the phase-velocity dispersion curve generated from the velocity model mTNA. The dotted lines in panels (B) and (C) are for spectral amplitudes and the time-shifted time series of O06A (near station), respectively. 
711

712

713

714

The solid lines are for the (unaltered) M11A waveform.

Figure 5: Reduced $\chi^{2}$-misfit, as defined in equation 8 , as a function of the trace of the resolution matrix for inversions of phase velocities measured at 44 s period. The solid thick curve was obtained by inverting equation 2 only for the $0 \Psi$ term. Different values of the trace of the resolution matrix were obtained by varying the level of damping applied (lower damping corresponding to higher values of the trace of $\mathbf{R}$. The dashed grey curve corresponds to inversions for the $0 \Psi$ and $2 \Psi$ terms and a fixed (moderate) amount of damping imposed on the $0 \Psi$ term. Changes in the $2 \Psi$ damping factor provided different values for the trace of $\mathrm{R}$. The thin solid line was obtained by inversions for the $0 \Psi, 2 \Psi$, and $4 \Psi$ terms, with moderate $0 \Psi$ and $2 \Psi$ smoothing factors kept fixed, and by varying the damping on the $4 \Psi$ terms. The crosses mark our "preferred" models in the $0 \Psi+2 \Psi$ and the $0 \Psi+2 \Psi+4 \Psi$ inversions. With an F-test we determined that the reduction in misfit between the "preferred" models is significant.

Figure 6: Azimuthally anisotropic phase velocity maps between $16 \mathrm{~s}$ and $102 \mathrm{~s}$ period. The background colors represent the isotropic $(0 \Psi)$ part of equation 2. The black lines show the fast direction of propagation for Rayleigh waves calculated from the $2 \Psi$ terms of equation 2. The reference phase velocity, calculated using the reference mTNA model, is given on top of each each map. 
Figure 7: Ray coverage obtained between $16 \mathrm{~s}$ and $102 \mathrm{~s}$ period. The location of the TA stations is shown by the black triangles. The background color is the isotropic $(0 \Psi)$ part of the maps (see Figure 6).

Figure 8: Partial derivatives for fundamental-mode Rayleigh wave phase velocities with respect to $V_{S}$ based on velocity model mTNA. They are plotted as a function of depth for the different periods analyzed.

Figure 9: Peak and mean amplitudes for the $2 \Psi$ part of the phase velocity maps obtained at selected periods between $16 \mathrm{~s}$ and $102 \mathrm{~s}$

Figure 10: Synthetic tests for inversions done at $18 \mathrm{~s}$ and $44 \mathrm{~s}$ period. Input models are on the left $(\mathrm{A}, \mathrm{C}$, and $\mathrm{E})$ and the outputs are on the right $(\mathrm{B}, \mathrm{D}$, and $\mathrm{F})$. Input model $\mathrm{A}$ was created using the results of the real data inversion at $18 \mathrm{~s}$. The anisotropy of models $\mathrm{C}$ and $\mathrm{E}$ is identical to that of model A but the background phase velocity is different. Model $\mathrm{C}$ assumes a uniformly negative phase velocity anomaly and model $\mathrm{E}$ assumes a positive velocity anomaly associated with the anisotropy-low in central Nevada, similar to what could be expected from a model such as the one described by West et al. (2009). 


\begin{tabular}{|c|c|c|c|c|c|c|}
\hline Event date & Event time & Location & Latitude & Longitude & Depth $(\mathrm{km})$ & Magnitude \\
\hline 2006-09-10 & $14: 56: 07.4$ & Gulf of Mexico & 26.33 & -86.58 & 10 & 5.6 \\
\hline $2006-10-15$ & $17: 07: 48.4$ & Hawaii & 19.82 & -156.03 & 29 & 6.7 \\
\hline 2006-11-19 & $18: 57: 33.7$ & Central East Pacific Rise & -4.49 & -104.75 & 10 & 6.2 \\
\hline $2006-12-03$ & $20: 52: 20.6$ & Guatemala & 14.08 & -91.24 & 62.8 & $5.8(\mathrm{Mb})$ \\
\hline 2007-01-31 & $03: 15: 55.7$ & Kermadec Islands & -29.59 & -177.93 & 34.0 & 6.3 \\
\hline 2007-02-04 & $20: 56: 58.8$ & Cuba Region & 19.48 & -78.30 & 10.0 & 5.9 \\
\hline $2007-02-24$ & $02: 36: 22.0$ & Off Coast of Northern Peru & -6.9 & -80.32 & 23 & 6.1 \\
\hline 2007:04:07 & $07: 09: 26.1$ & Azores Islands Region & 37.36 & -24.50 & 8.0 & 5.9 \\
\hline 2007-04-13 & $05: 42: 23.0$ & Guerrero, Mexico & 17.3 & -100.1 & 28.80 & 5.8 \\
\hline $2007-04-25$ & $13: 34: 16.3$ & Vanatu Islands & -14.29 & 166.86 & 55 & 5.7 \\
\hline $2007-05-04$ & $12: 06: 52.6$ & North of Ascension Island & -5.52 & -14.87 & 7.0 & 5.9 \\
\hline $2007-05-12$ & $11: 31: 05.1$ & Eastern New Guinea Region & -5.52 & 146.12 & 43.6 & 5.3 \\
\hline $2007-05-17$ & $19: 29: 10.2$ & Kermadec Islands & -30.60 & -178.22 & 40.7 & 5.6 \\
\hline $2007-05-27$ & $18: 12: 35.0$ & Tonga Islands Region & -20.05 & -174.53 & 6.8 & $5.8(\mathrm{Mb})$ \\
\hline 2007-06-08 & $13: 32: 01.7$ & Near Coast of Guatemala & 13.80 & -90.84 & 47.8 & 5.4 \\
\hline $2007-06-13$ & $19: 29: 46.0$ & Near Coast of Guatemala & 13.63 & -90.73 & 23 & 6.5 \\
\hline $2007-06-14$ & $13: 37: 41.5$ & Southeast of Easter Island & -36.23 & -99.96 & 10.0 & 5.4 \\
\hline $2007-06-14$ & $17: 41: 05.0$ & New Britain Region, Papua New Guinea & -5.71 & 151.61 & 41.0 & 5.6 \\
\hline $2007-07-03$ & $08: 26: 00.7$ & Central Mid-Atlantic Ridge & 0.71 & -30.24 & 10.0 & 5.9 \\
\hline $2007-07-06$ & $17: 40: 54.8$ & Samoa Islands Region & -16.30 & -172.82 & 10.0 & 5.1 \\
\hline 2007-07-09 & $06: 50: 50.7$ & South of Fuji Islands & -26.29 & -178.14 & 10.0 & 5.3 \\
\hline 2007-08-09 & $17: 25: 05.5$ & Northern Mid-Atlantic Ridge & 25.81 & -44.99 & 10.0 & 5.1 \\
\hline $2007-08-12$ & $12: 05: 26.7$ & Santa Cruz Islands & -11.35 & 166.15 & 42.0 & 5.7 \\
\hline 2007-08-19 & $01: 22: 38.2$ & Near Coast of Peru & -13.54 & -76.47 & 11.00 & 5.4 \\
\hline 2007-08-19 & $20: 11: 44.5$ & Near Coast of Peru & -13.58 & -76.38 & 35.0 & 5.2 \\
\hline 2007-09-01 & $01: 56: 49.0$ & Northern Mid-Atlantic Ridge & 27.79 & -44.04 & 10.0 & 5.0 \\
\hline 2007-09-01 & $19: 14: 30.4$ & Gulf of California & 25.14 & -109.67 & 9.0 & 5.9 \\
\hline 2007-09-10 & $01: 49: 10.5$ & Near West Coast of Columbia & 2.91 & -78.15 & 15.0 & 6.7 \\
\hline
\end{tabular}

Table 1: Selected events date, time, locations, and magnitudes. Unless otherwise specified, magnitudes are Ms magnitudes reported by the Iris DMC. 


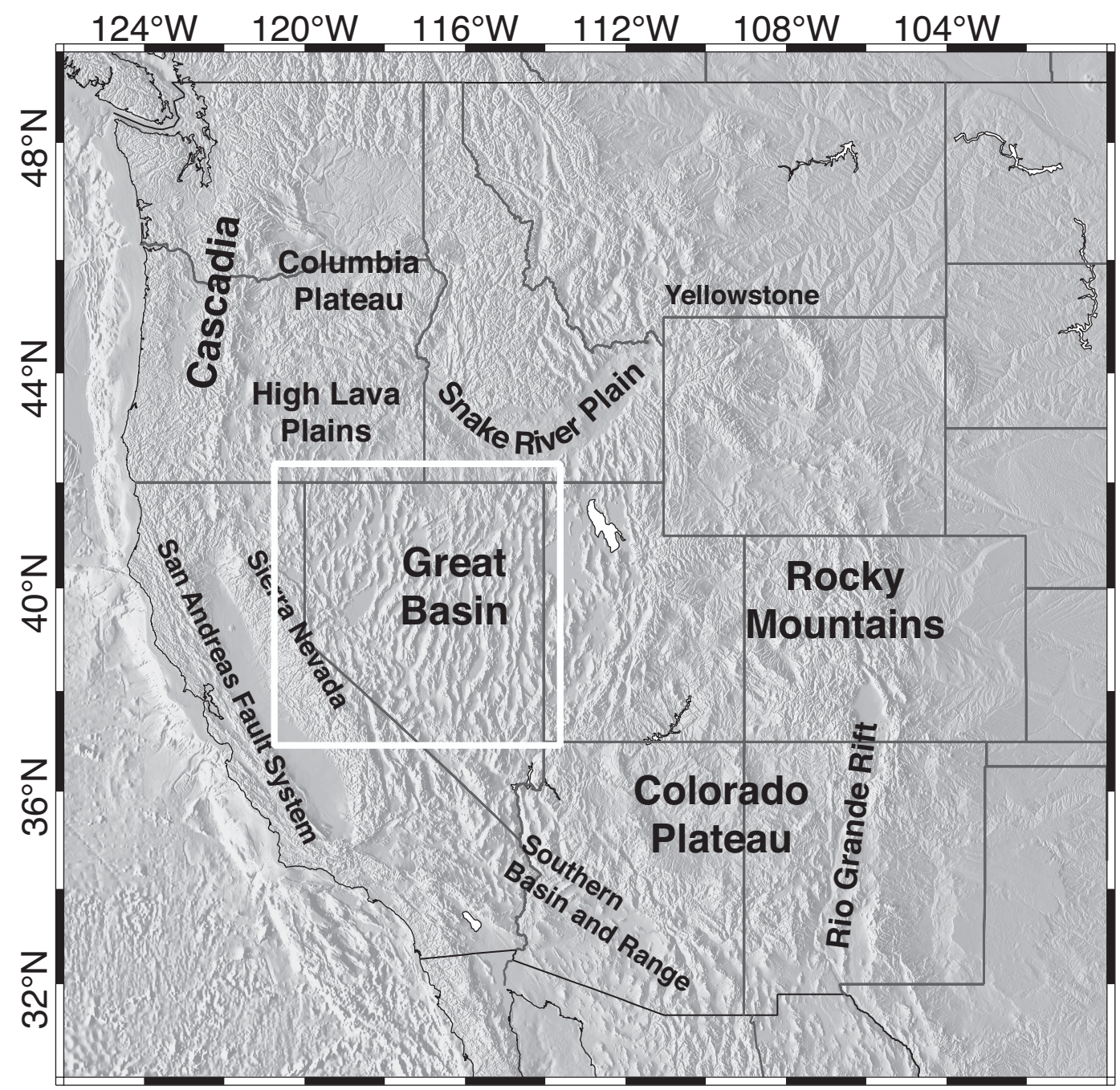

Figure 1: 

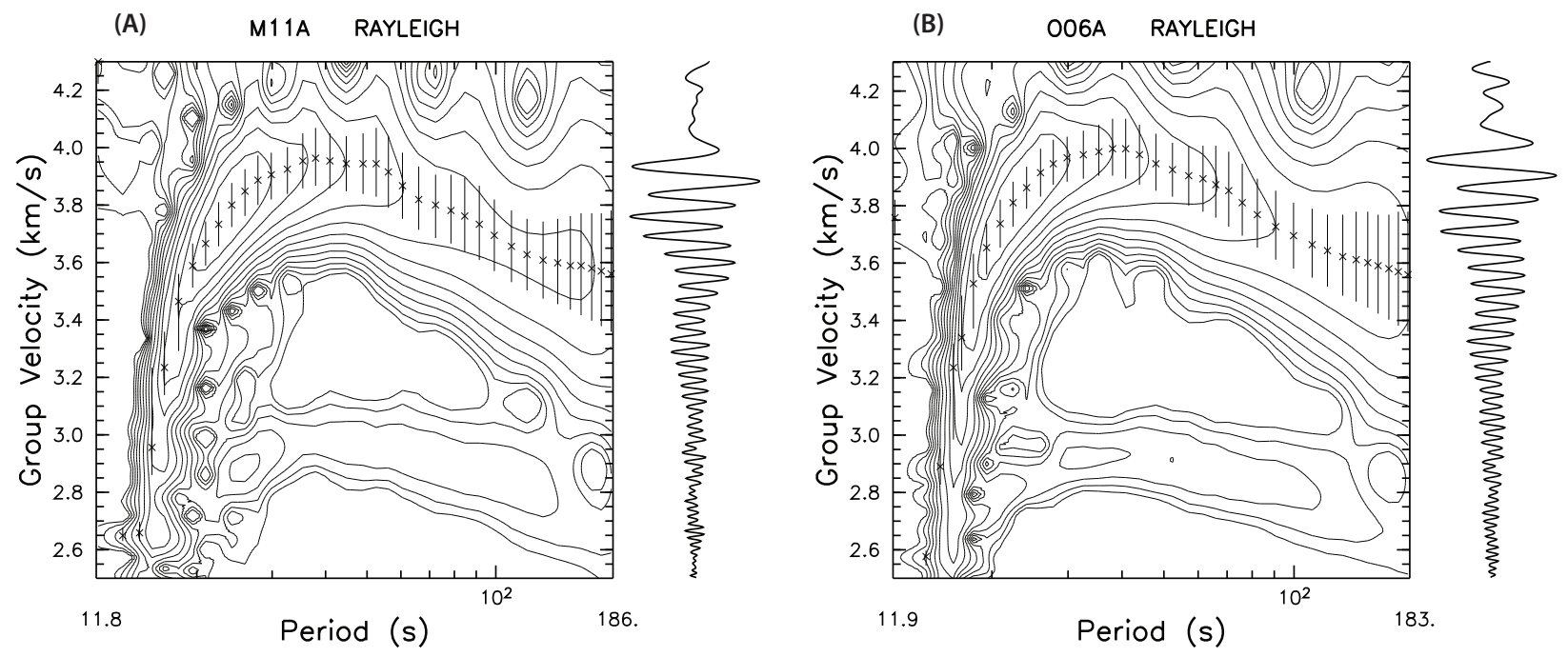

Figure 2:

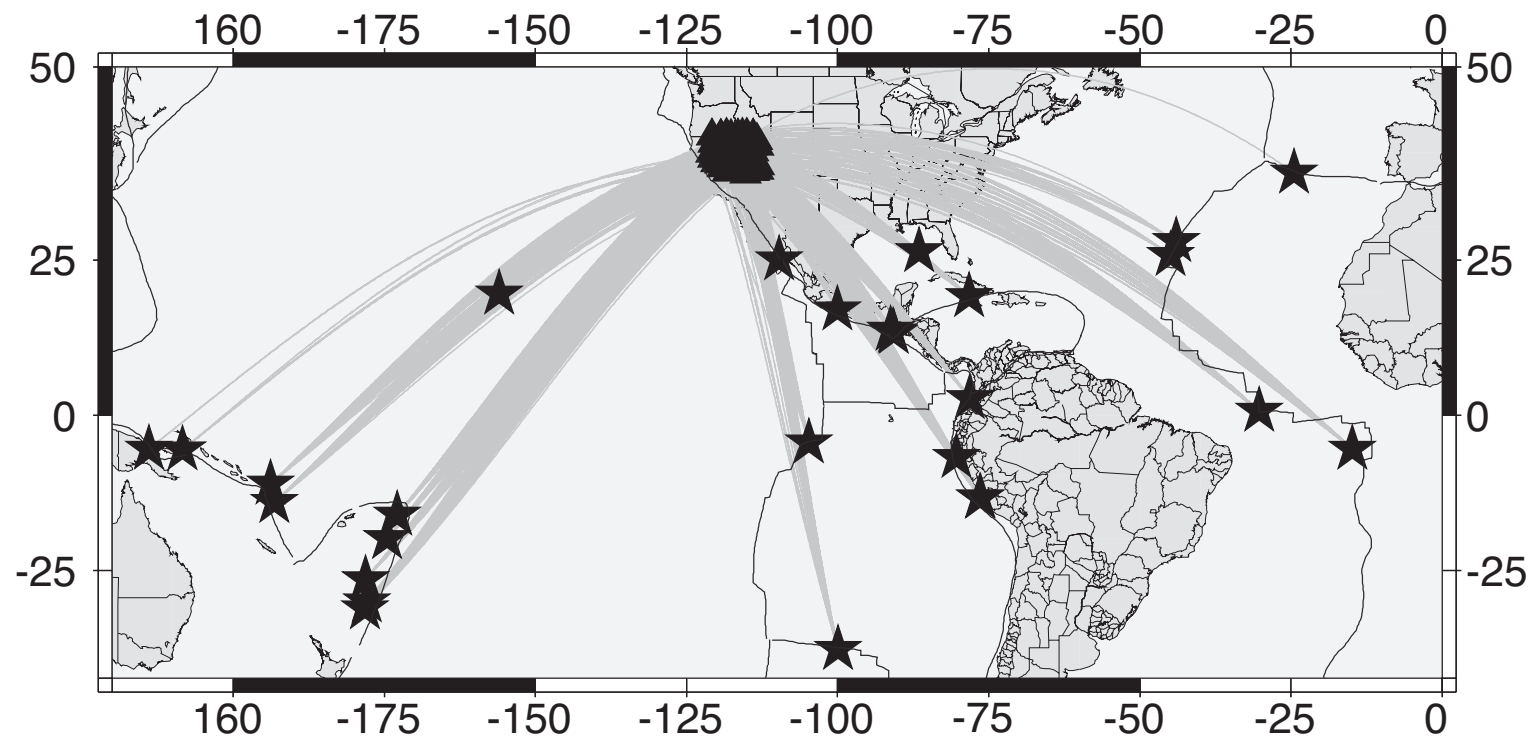

Figure 3: 

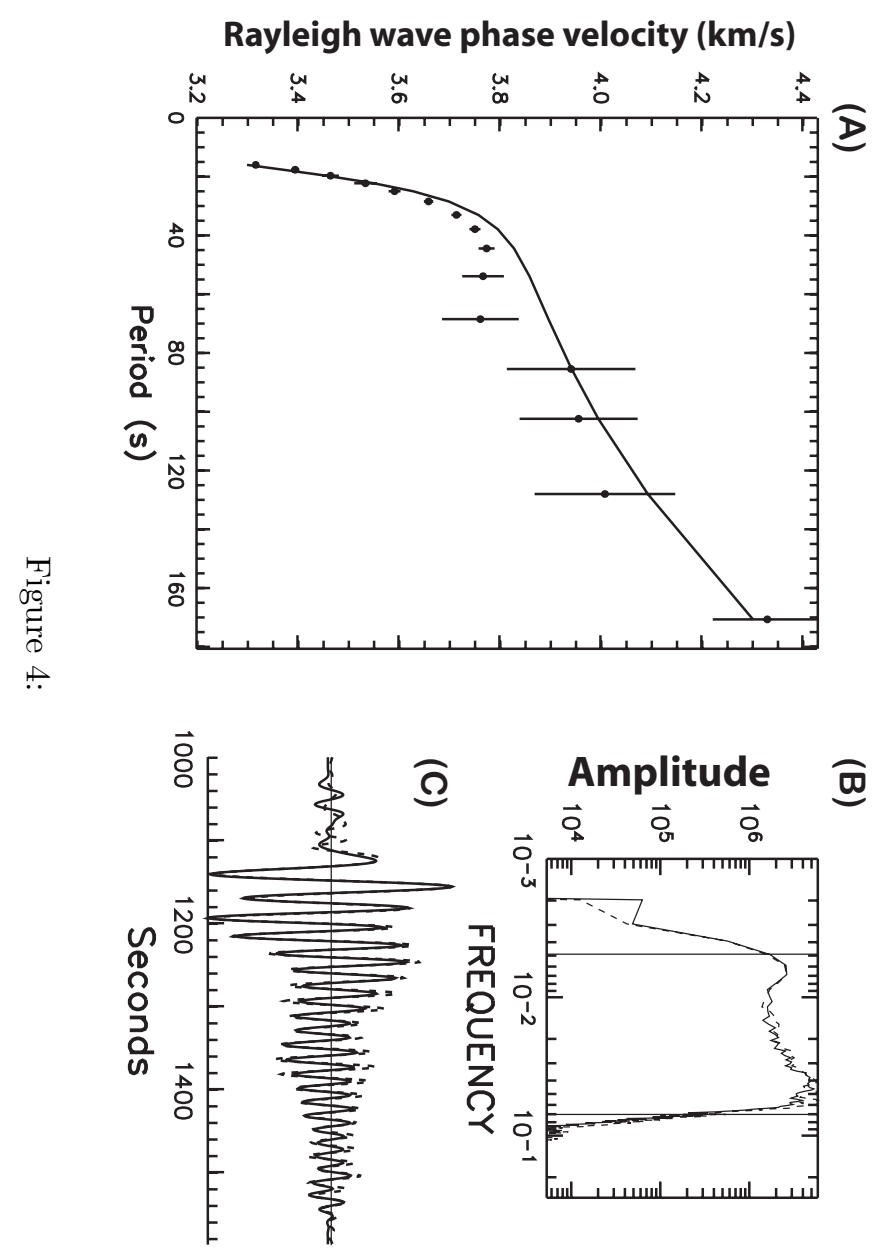


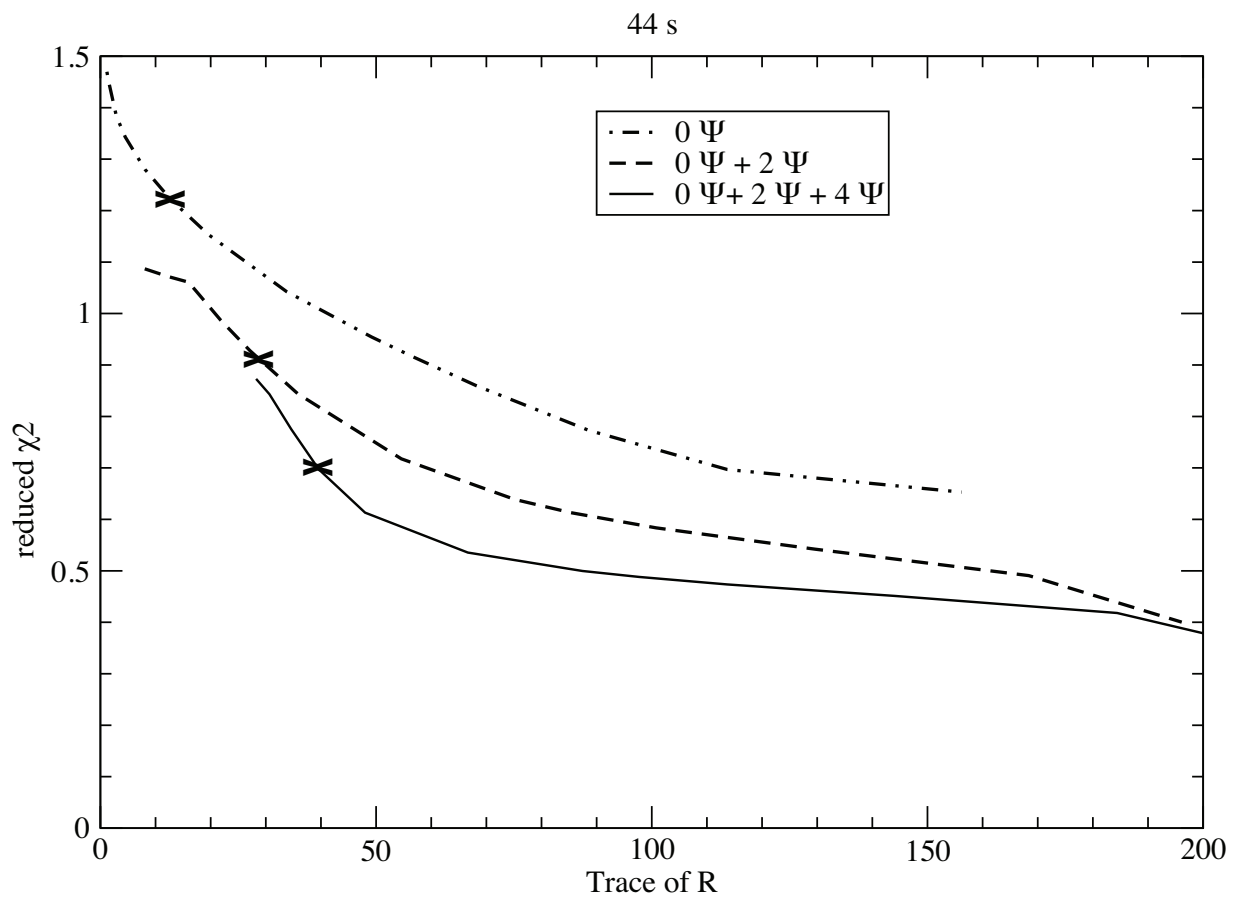

Figure 5: 

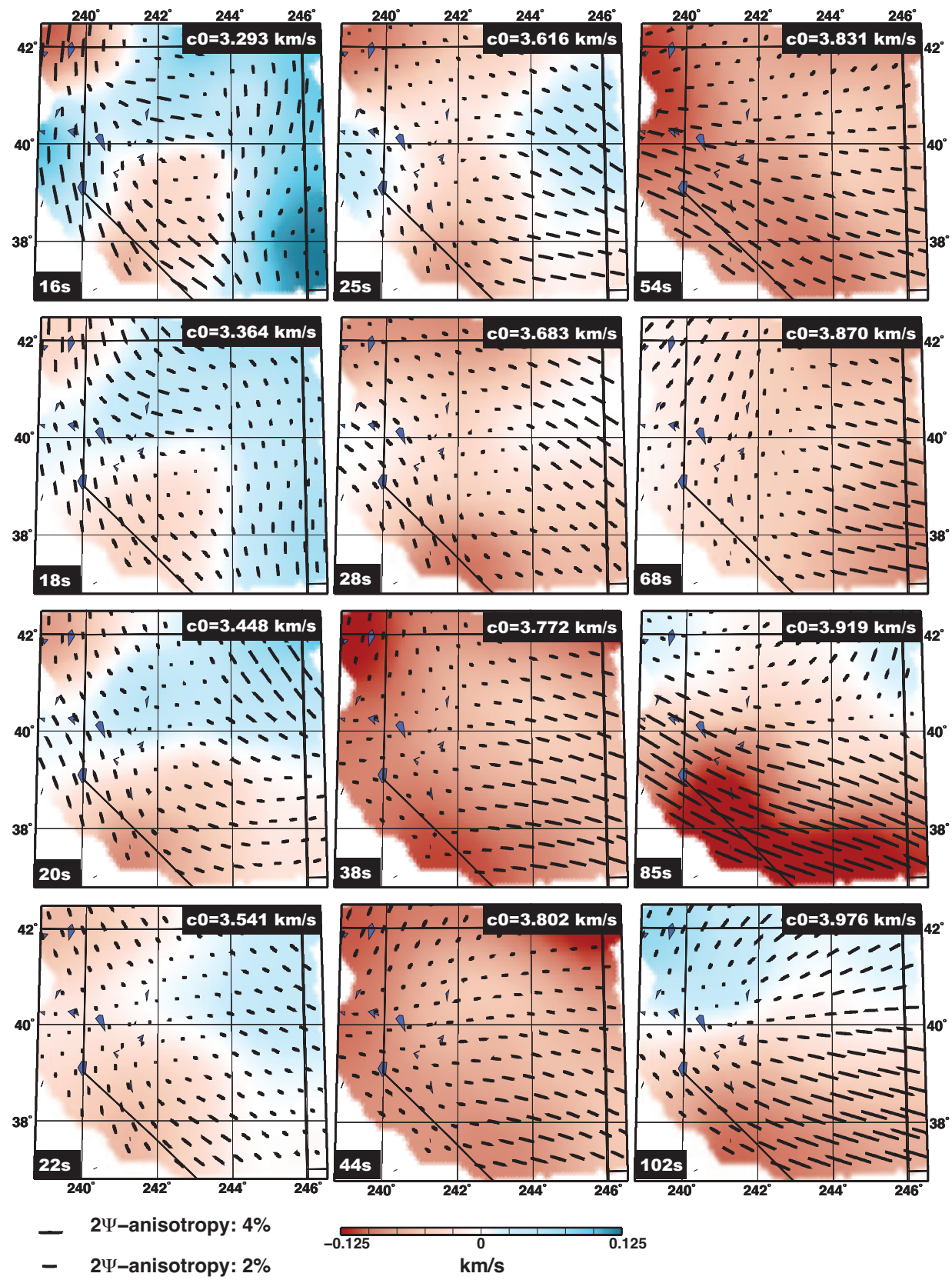

Figure 6: 

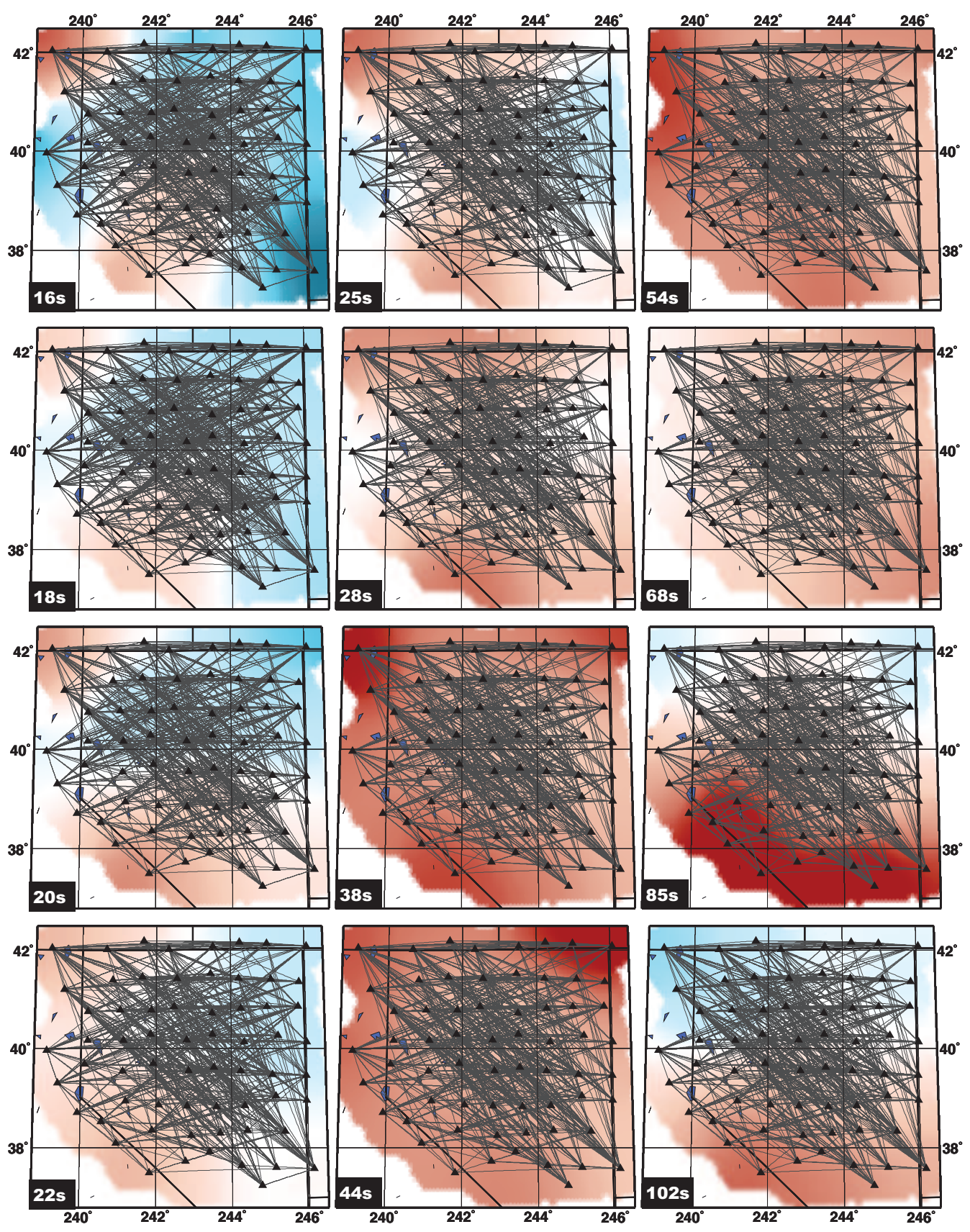

Figure 7: 


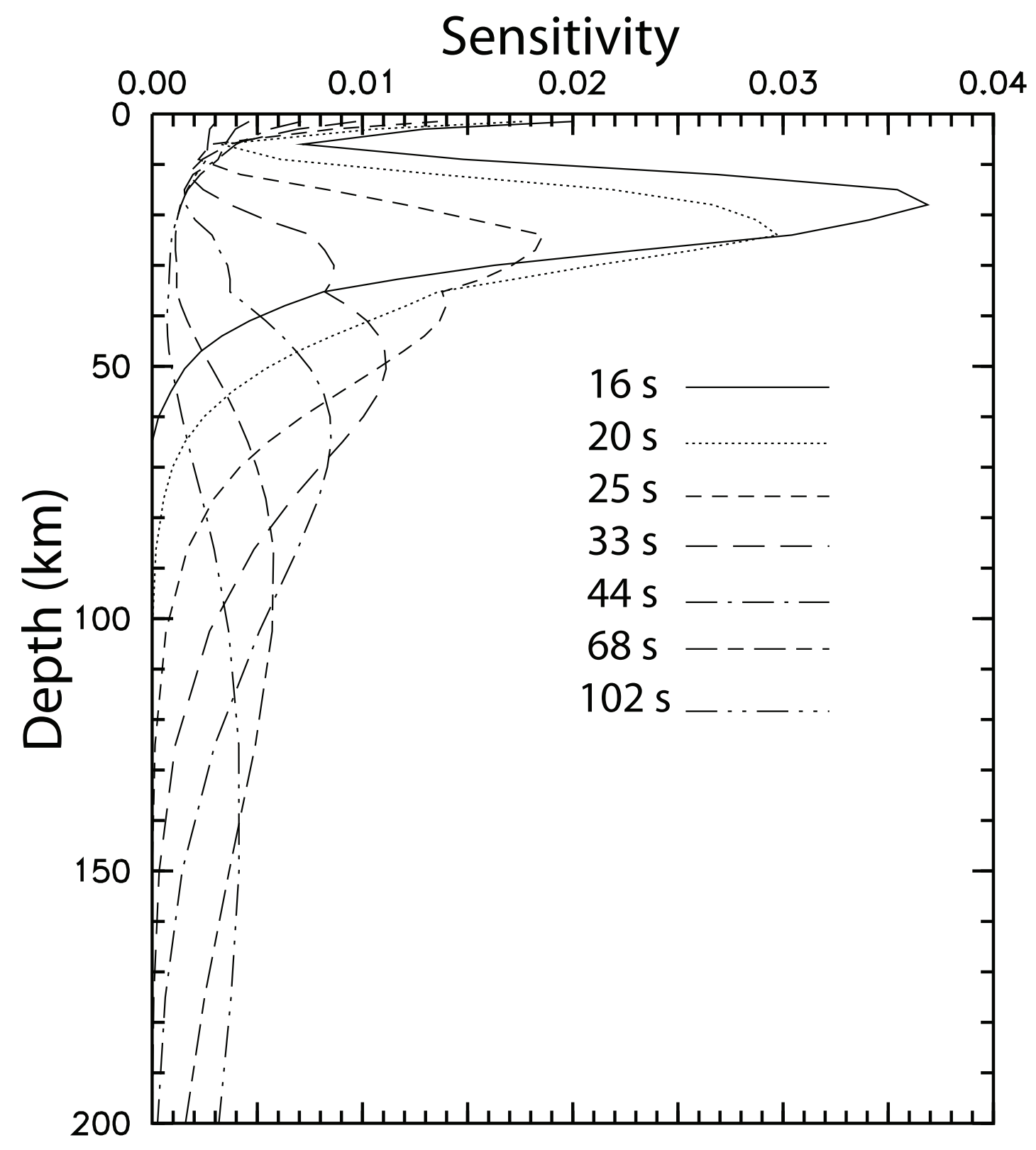

Figure 8: 


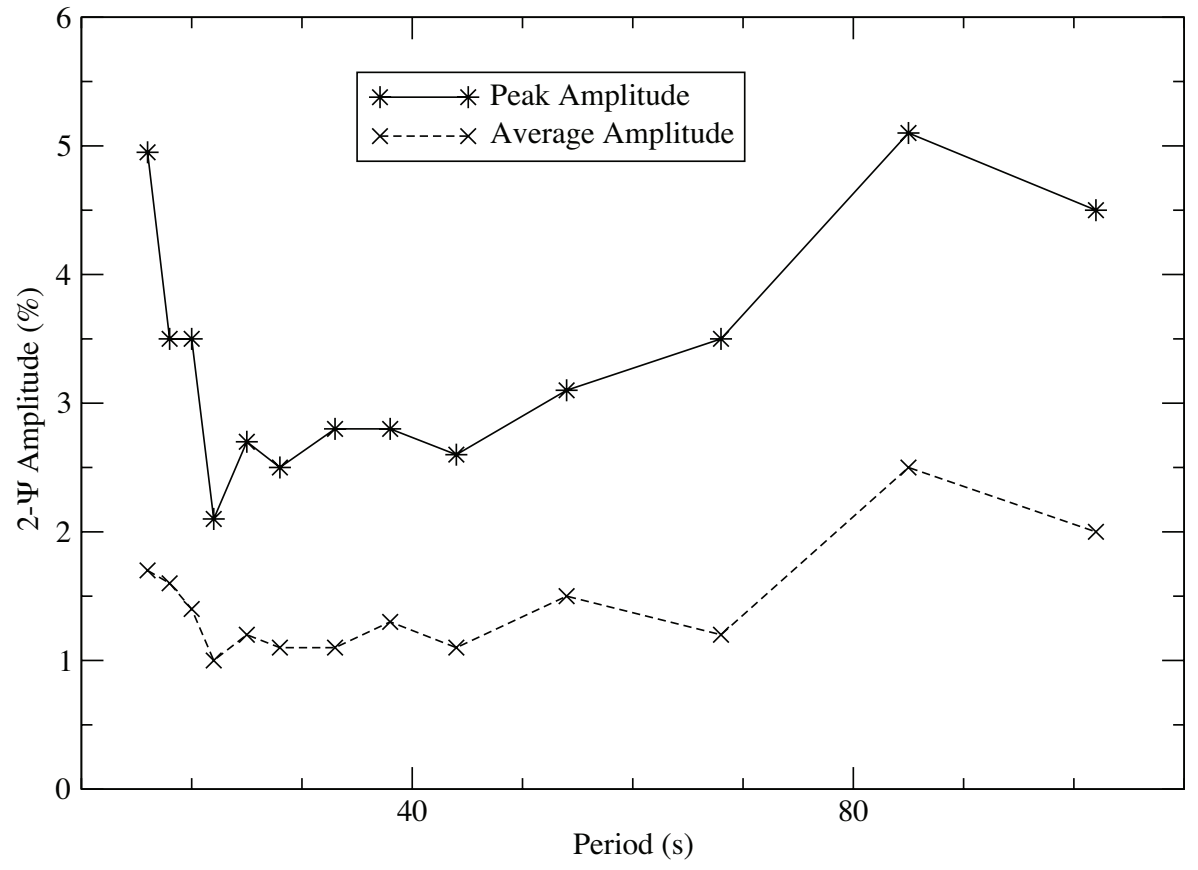

Figure 9: 

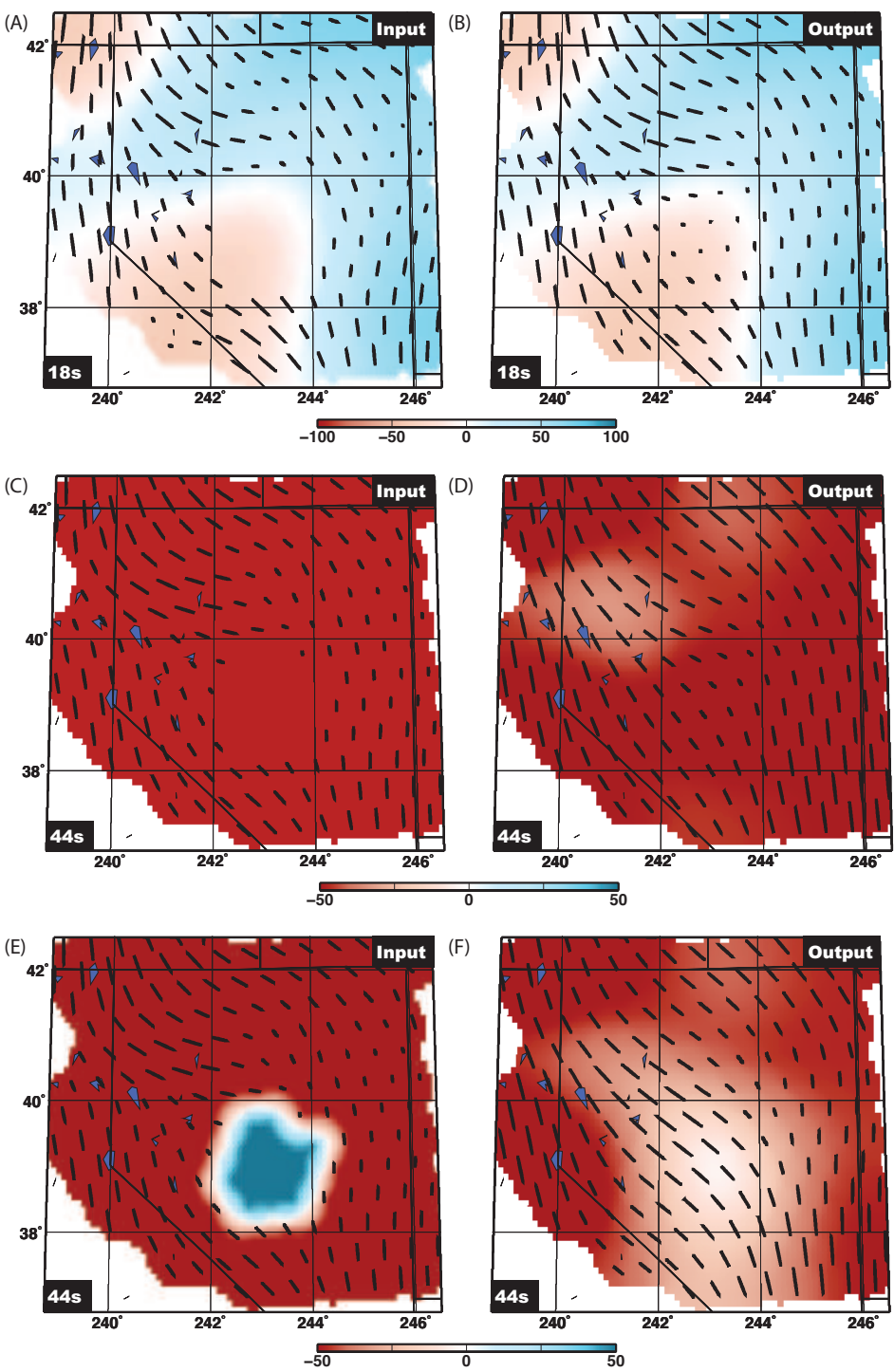

Figure 10: 
$124^{\circ} \mathrm{W}$

$120^{\circ} \mathrm{W}$

$116^{\circ} \mathrm{W}$

$112^{\circ} \mathrm{W}$

$108^{\circ} \mathrm{W}$ $104^{\circ} \mathrm{W}$

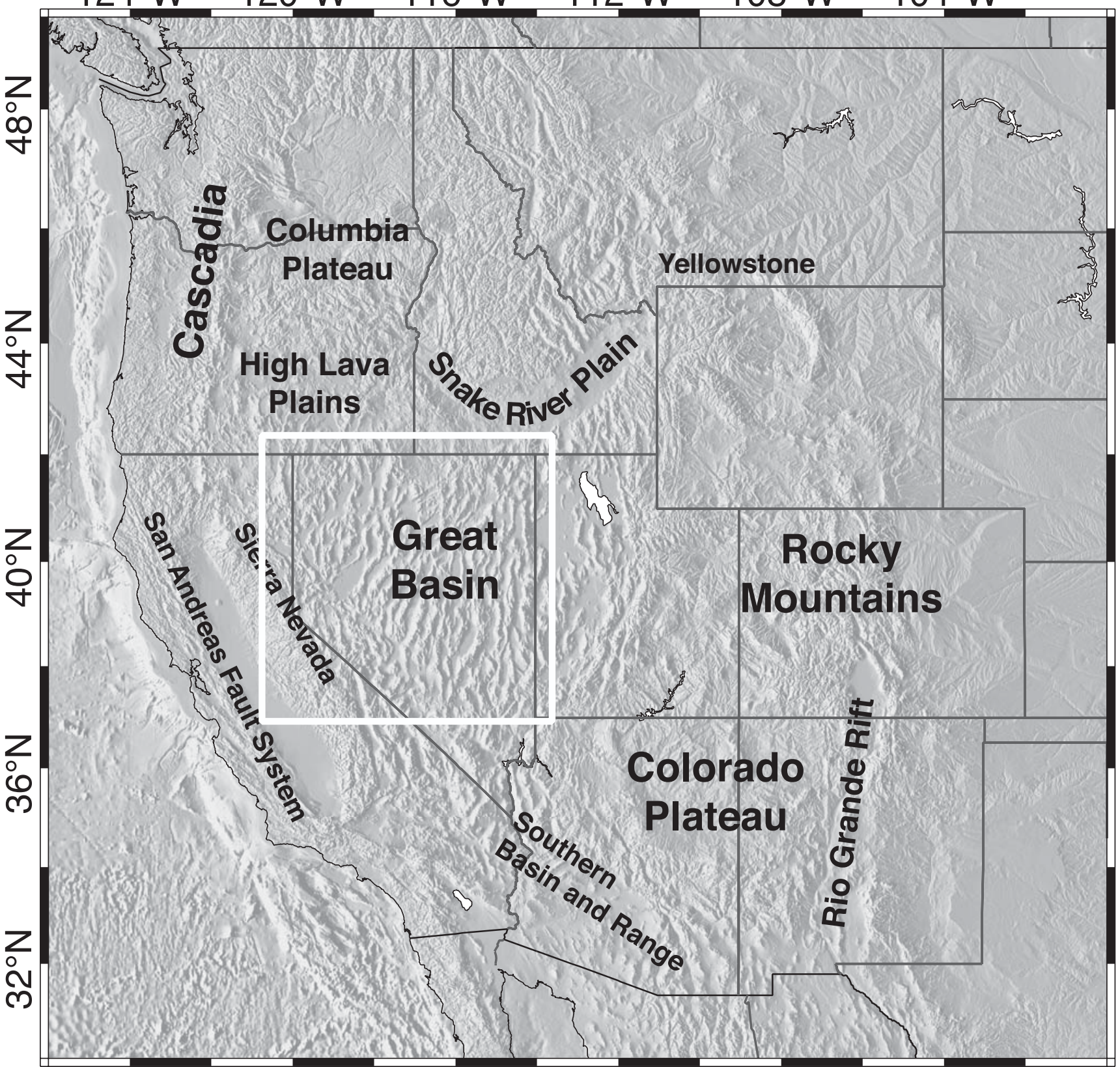


(A)

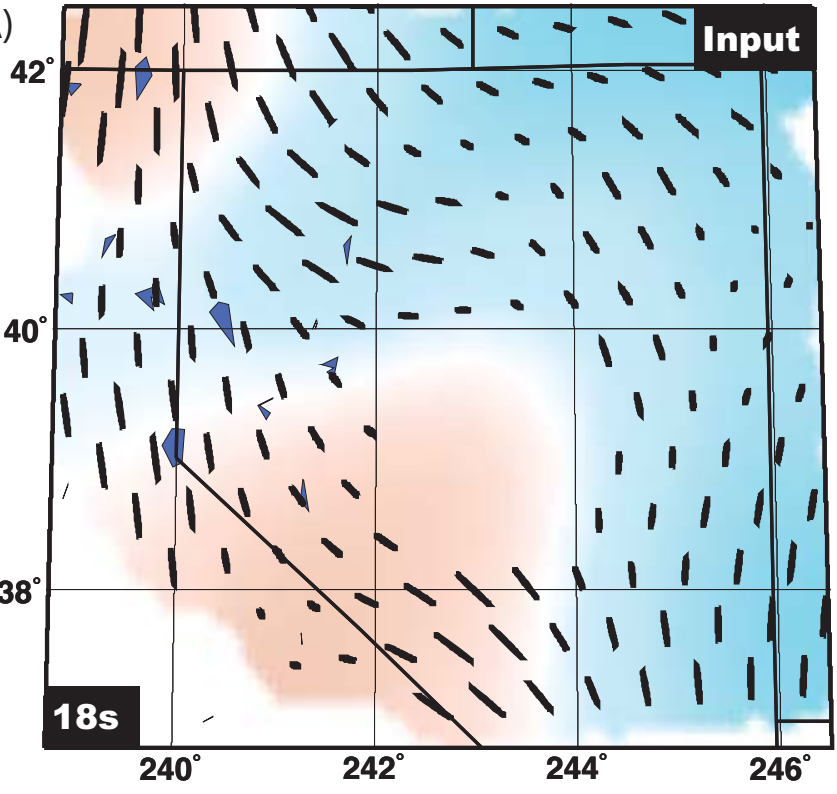

(B)

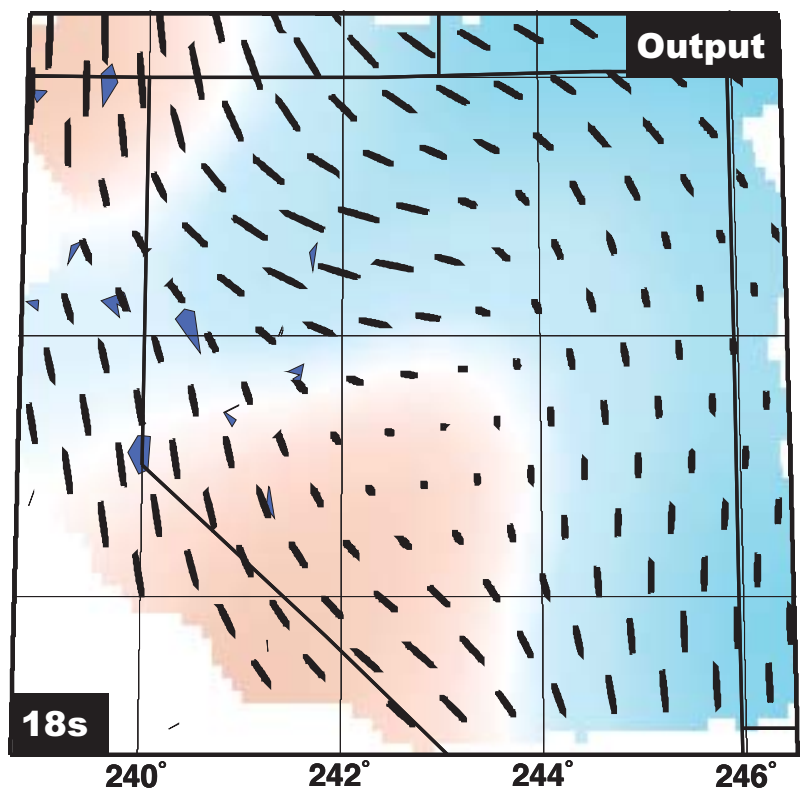

\section{(C)}

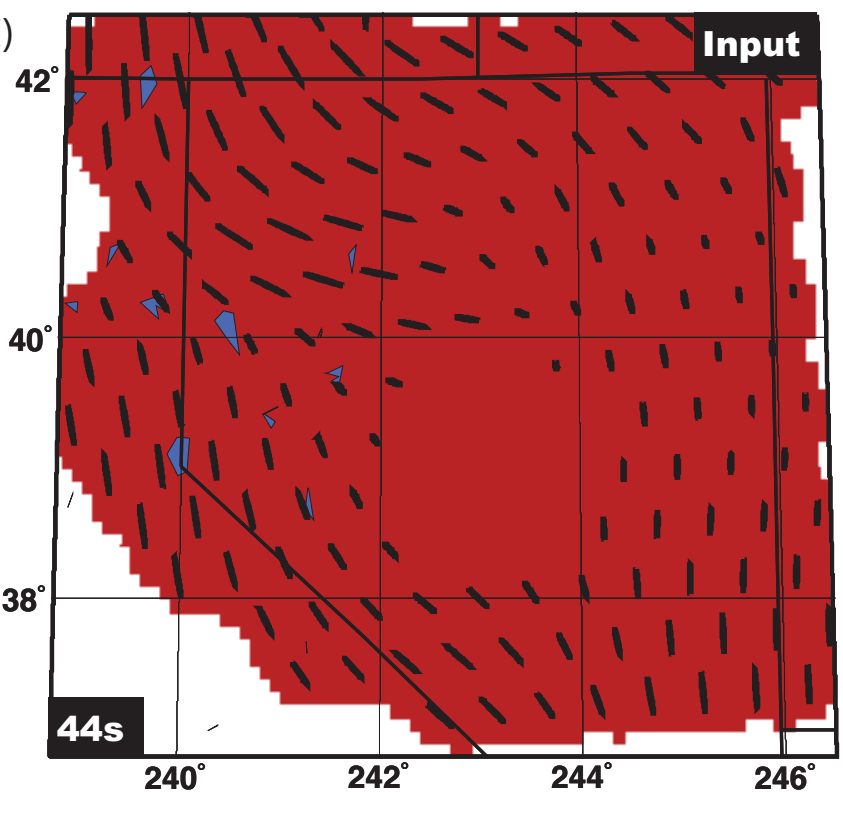

(D)

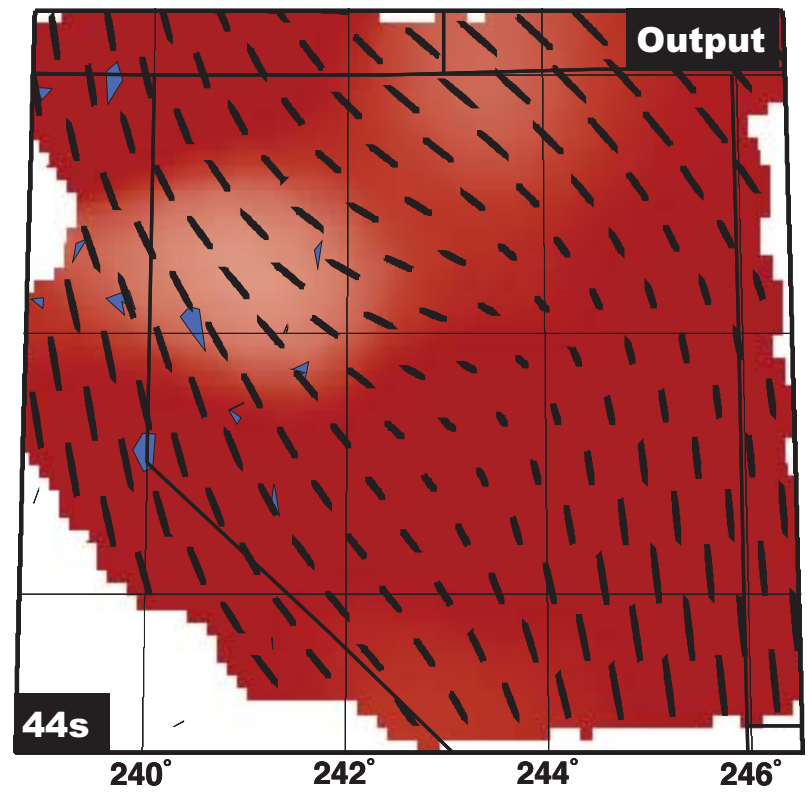

(E)

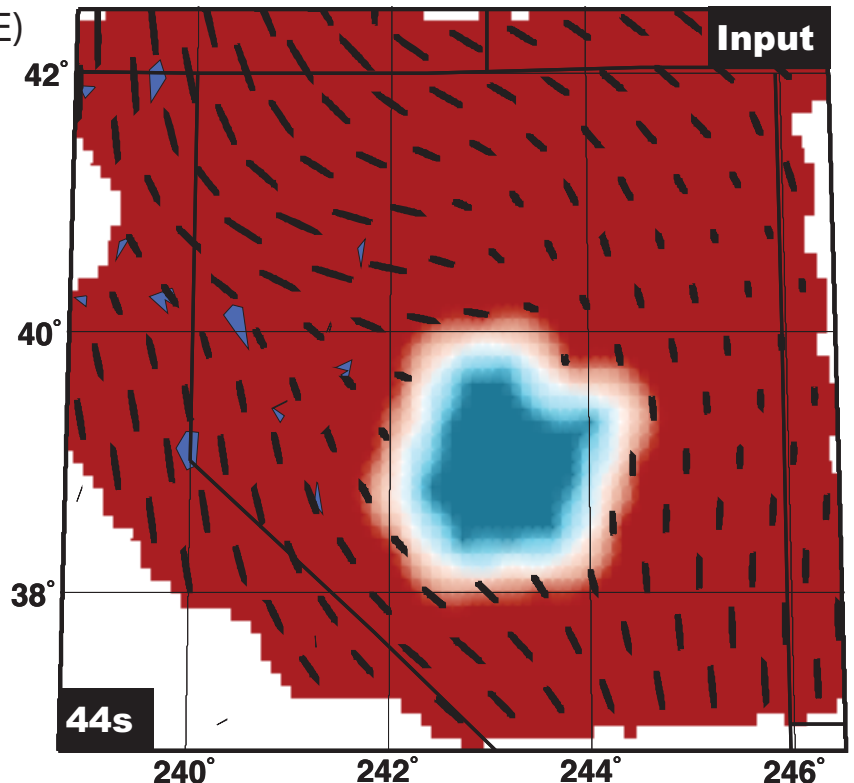

(F)

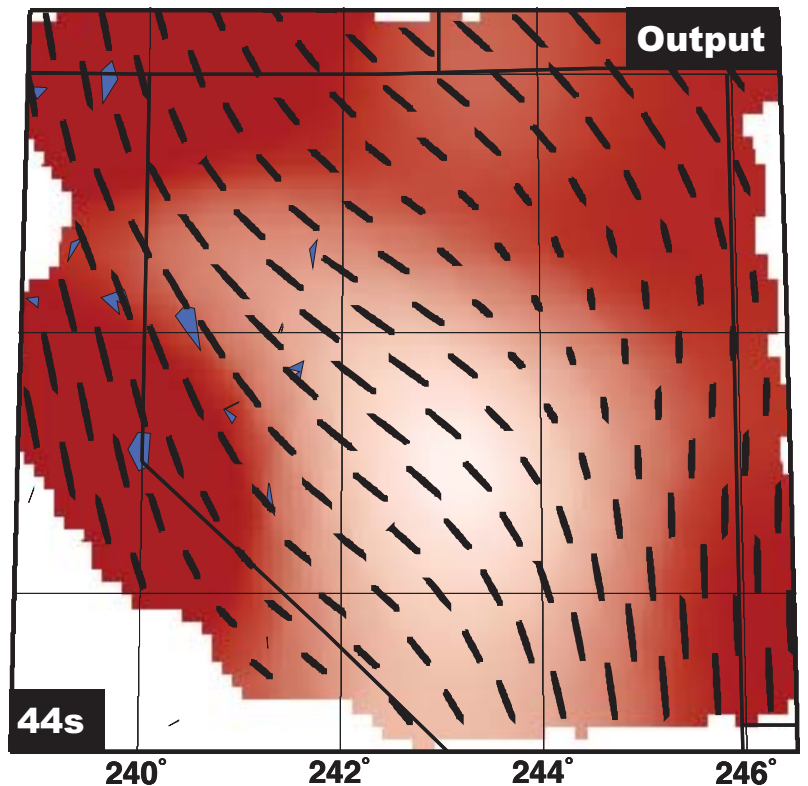


O06A RAYLEIGH
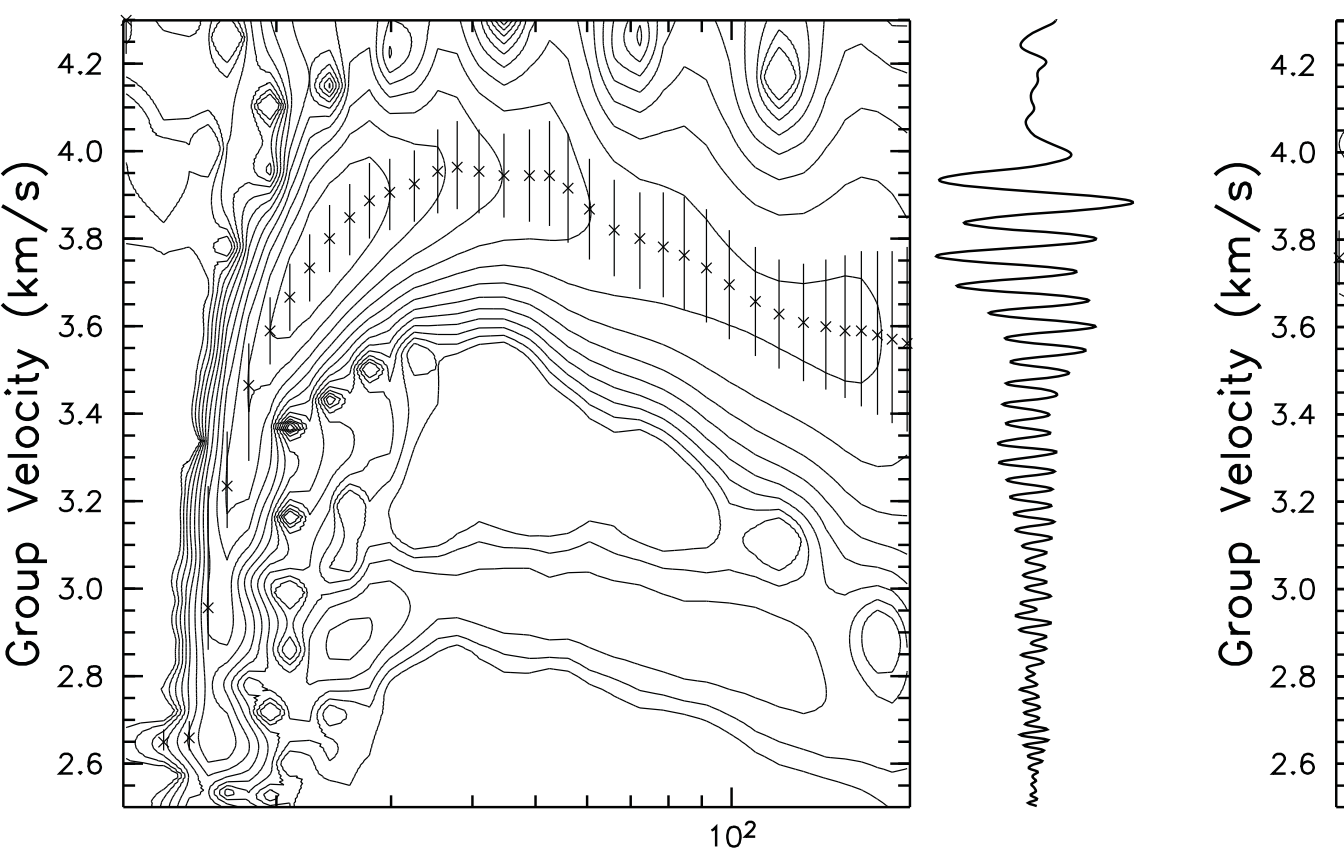

Period (s)

186.
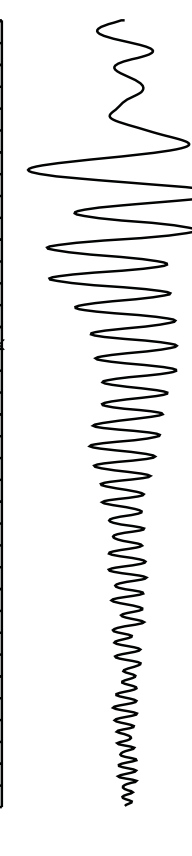

Period (s)
183. 


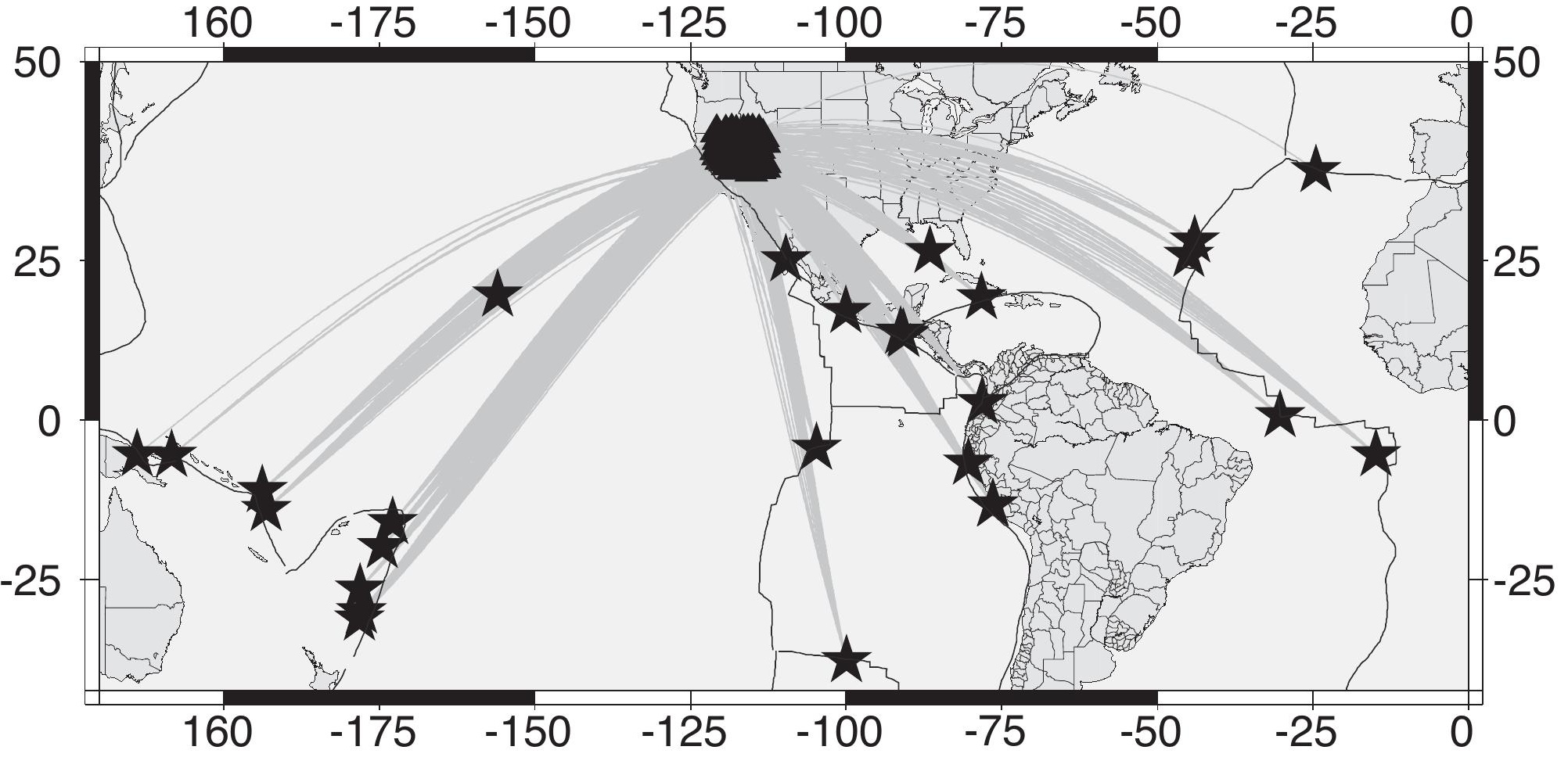


(A)

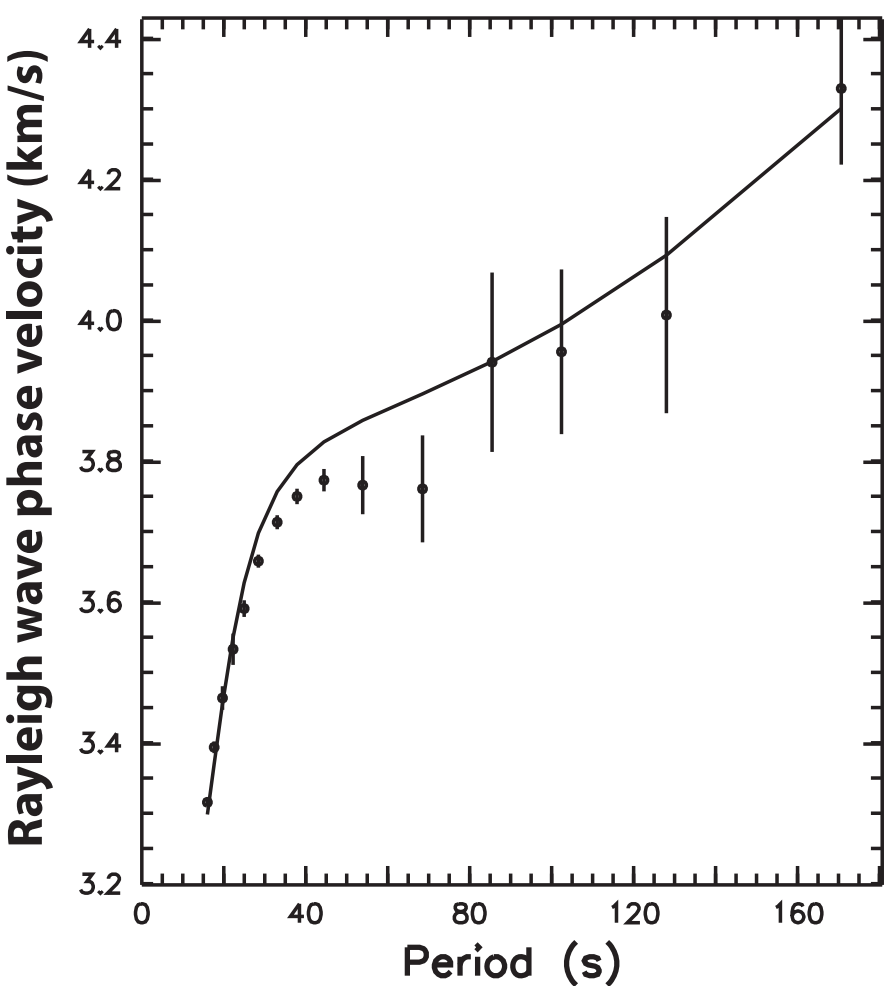

(B)
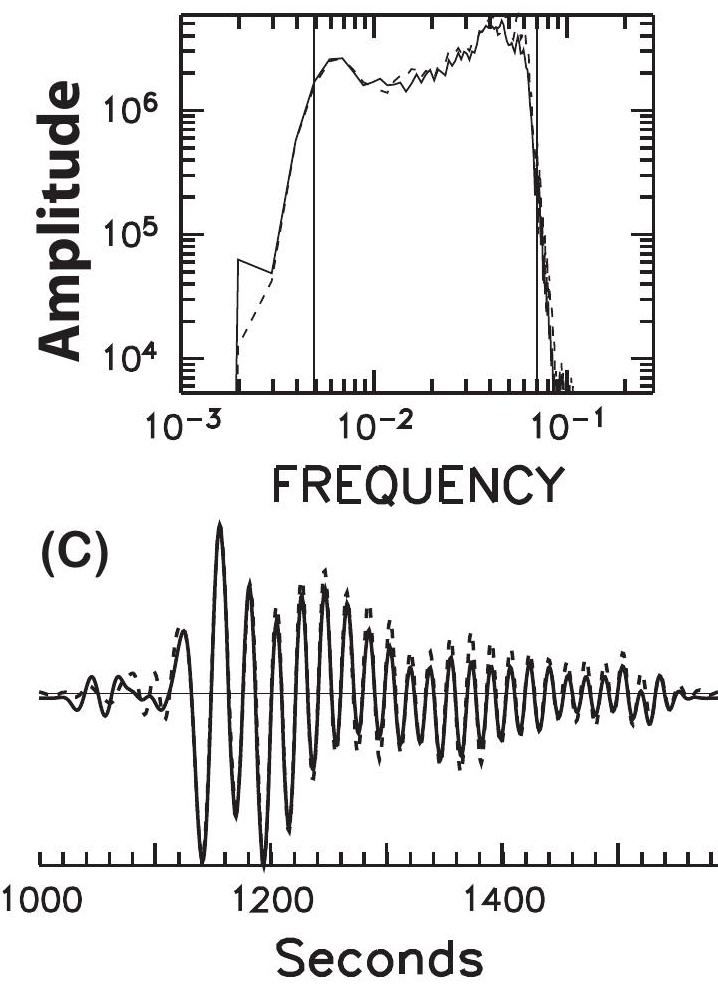
$44 \mathrm{~s}$

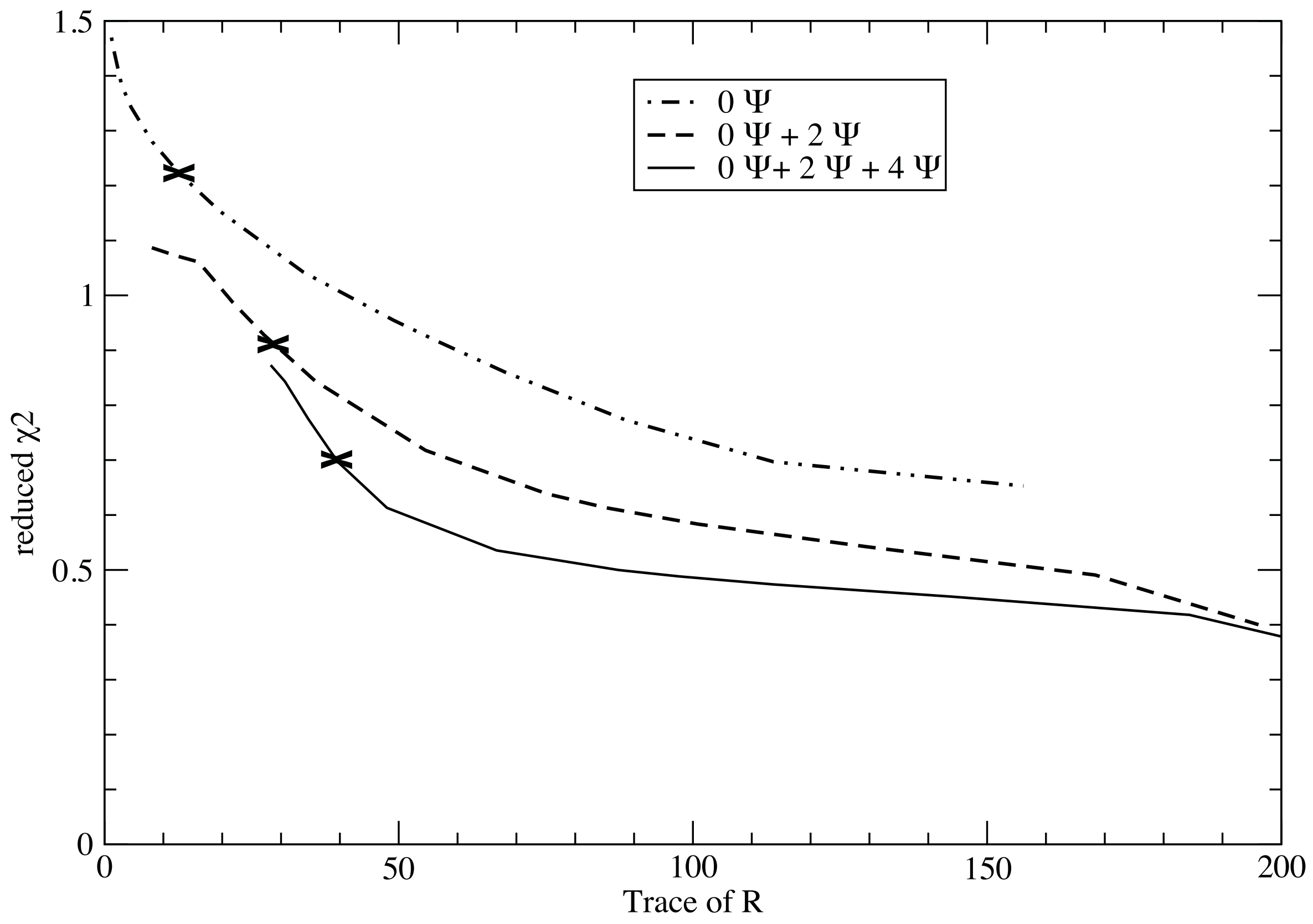




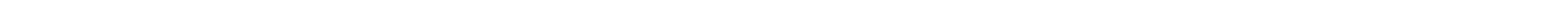




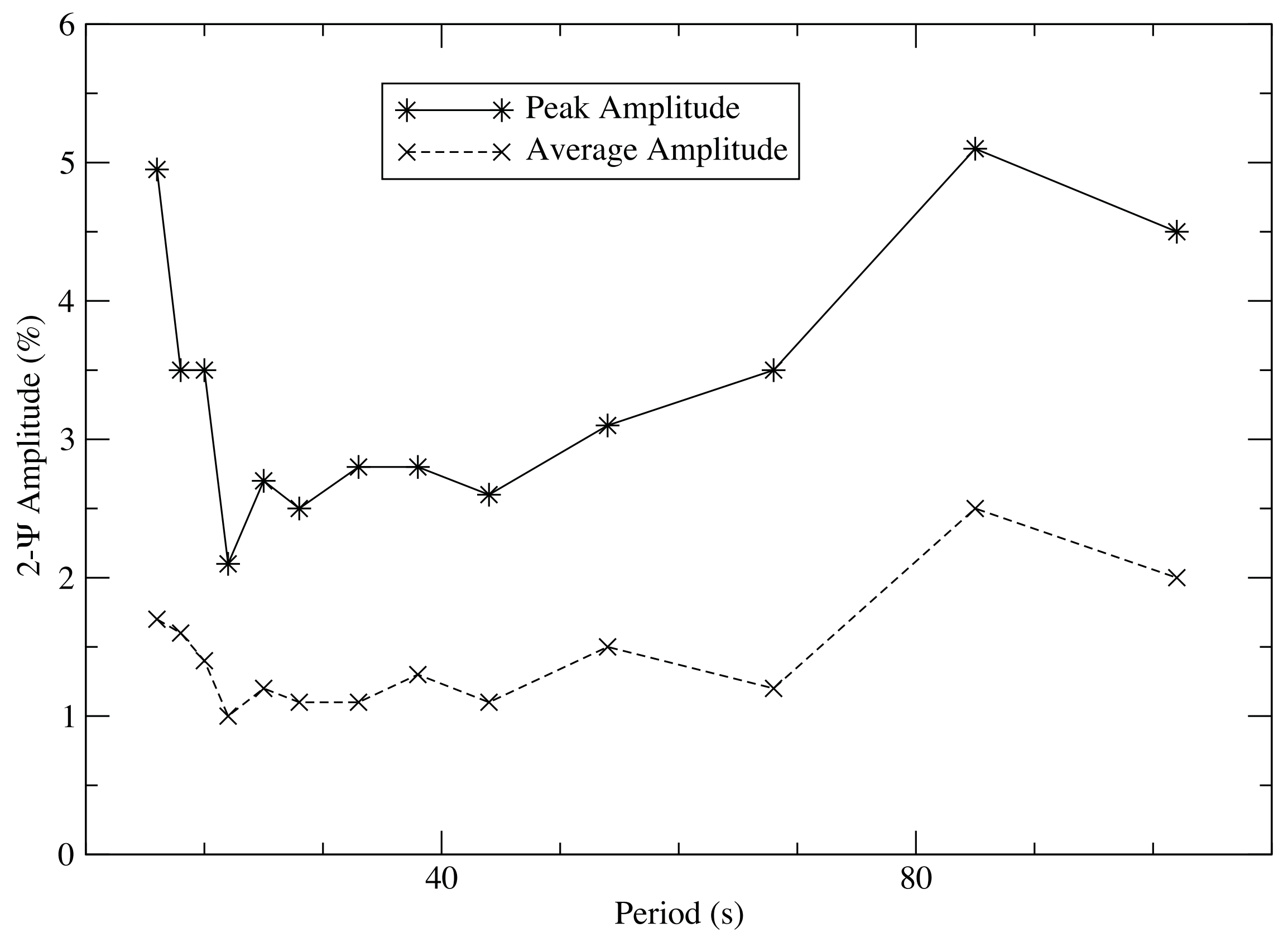

